\title{
Employment Dynamics of Married Women in Europe ${ }^{1}$
}

\author{
Pierre-Carl Michaud, \\ RAND \\ Konstantinos Tatsiramos \\ Institute for the Study of Labor (IZA)
}

\begin{abstract}
We use longitudinal data from the European Community Household Panel (1994-2001) to analyze the intertemporal labor supply behavior of married women in seven European countries (Denmark, France, Germany, Italy, Netherlands, Spain, and United Kingdom) We find that North-South differences in Europe have little to do with different employment penalties to motherhood. Although such effects vary considerably across countries and are weakly consistent with prevailing childcare institutions in Northern countries, North-South differences in employment are most pronounced among low-skill females irrespective of the presence of children. Co-movements in regional employment and wages in Southern Europe (Spain and Italy) suggest that weak demand (few opportunities), low wages and social norms hostile to female employment are more likely to explain low female labor force participation of married women in those countries.
\end{abstract}

Keywords : intertemporal labor supply, female employment, dynamic binary choice models, initial conditions.

JEL Codes : C23, C25, D91, J22

${ }^{1}$ Corresponding Author: Pierre-Carl Michaud 1776 Main Street m5e, Santa Monica CA 90407; michaud@ rand.org. We thank Raquel Fonseca, participants at ESPE 2006 conference, and seminars at IZA Bonn, CentER and GAINS Maine University for comments. Remaining errors are our own. Tatsiramos acknowledges financial support provided through the European Community's Human Potential Programme under contract HPRN-CT-2002-00235, [AGE]. 


\section{Introduction}

In 2000, the European Union set a 60\% female employment rate target for 2010 under the so-called Lisbon Agenda. Employment rates vary considerably across European countries and only a small fraction of that gap is accounted for by differences in unemployment rates. In 1999, the female unemployment rate for the age group 25-54 was $12.7 \%$ in Italy, while it was practically the same in France (12.6\%) (OECD Labor Market Statistics, 1999). However, both countries differ substantially in their female employment rates (near 70\% in France across the 1994-2001 period and closer to $45-50 \%$ for Italy).

Particularly for Mediterranean countries, the Lisbon targets appear relatively ambitious. ${ }^{2}$ Pissarides et al. (2003) estimate that the observed increase in the 1990s, if sustained, can help close the gap by a third in 2010. Since this is probably insufficient to meet the target, more should be known about what explains the differences across countries and what can potentially increase employment of women in Europe. Needless to say, this goes beyond enabling countries to meet somewhat arbitrary employment targets.

In this paper we investigate the large differences in employment rates and their evolution in the 1990s using individual longitudinal data on a set of seven European countries (Denmark, France, Germany, Italy, Netherlands, Spain, and United Kingdom). Among the set of factors we consider, we pay particular attention to employment penalties related to childbearing and motherhood as well as demand-side factors. Similar to Hyslop (1999) for the United States, we consider the intertemporal nature of employment decisions, distinguishing true state dependence from unobserved heterogeneity, as well as the dynamic effect of births and motherhood.

It turns out that differences across countries are largest among low-skilled female workers, irrespective of the number of kids present in the household. The estimated effect of motherhood on employment is largest in countries that have generous child benefits, while these countries have also high employment rates. Our results suggest that the effect of motherhood cannot explain the large North-South differences in employment rates.

\footnotetext{
${ }^{2}$ From the OECD Employment Outlook of 2004 (p.296), women aged 15-64 in Italy had an employment rate of $46.3 \%$ in 2000 while this figure was $68.9 \%$ in the U.K.
} 
The dynamic effect of motherhood helps however explain differences in the North, particularly for the Netherlands, where females stay out of regular employment, working often very few hours per week, for many years after giving birth. This is in sharp contrast to the U.K. or France where recovery is faster and higher employment is observed.

To explain North-South differences, we turn to a regional-level analysis in Italy and Spain and show that increases in real wage and the fraction of part-time arrangements are able to explain most of the increase in employment in the 1990s. Both the regional and individual level results tend to suggest that demand, rather than supply factors, particularly for low-skilled females in the South, are likely to explain a large share of observed differences between the North and the South. We also find that social norms can play a role, as among low-skill workers in Italy (particularly in the South) where very low employment is observed, the attitudes towards female in employment are most negative.

Section 2 presents the data used in this analysis and some descriptive figures on employment across countries. Section 3 presents a simple theoretical model, based on an adaptation of the search model from Garibaldi and Wasmer (2004), showing the interplay between demand and supply factors in a dynamic setting with labor market frictions. This model leads to a well-defined econometric model similar to Hyslop (1999), which we discuss along with specific econometric issues in section 4. Results are discussed in section 5. Finally, section 6 concludes.

\section{The Data}

The analysis is based on individual data from the European Community Household Panel (ECHP, 1994-2001). The ECHP is a survey based on a standardized questionnaire that involves annual interviewing of a representative panel of households and individuals in each country, covering a wide range of topics including demographics, employment characteristics, education etc. In the first wave, a sample of some 60,500 nationally represented households - approximately 130,000 adults aged 16 years and over - were interviewed in the then 12 Member States. There are three characteristics that make the ECHP relevant for this study. That is, the simultaneous coverage of 
employment status, the standardized methodology and procedures yielding comparable information across countries and the longitudinal design in which information on the same set of households and persons is gathered. The sample is constructed as a balanced panel of all married and cohabiting females (referred to as married in what follows) aged between 20 and 45 years old with their husband employed continuously during all the available waves. We condition on the husband's employment status in order to avoid having to specify jointly employment decisions. This is similar to Hyslop (1999) and enables some comparison with intertemporal labor supply of married women in the U.S. However, we must acknowledge that the conclusions drawn from this analysis may not be applicable to other types of couples in Europe. Nevertheless, in most couples, the husband is usually employed continuously throughout the period covered. ${ }^{3}$

We first look at the general trend in employment rates stratified by education and the presence of kids in the household. We then document the persistence in employment decisions and relate it to employment rates. In what follows, employment is defined as working for more than 15 hours per week. Although there are many dimensions of labor supply choice one could look at (extensive vs. intensive margin, different hours cutoff), we use this definition because it measures stronger attachment to the labor force than a definition that would use a lower cutoff (say any positive hours). ${ }^{4}$

\subsection{Evolution of Employment Rates}

Table 1 shows the evolution of employment rates over time by country in the balanced panel from the ECHP. Generally, we observe an increase in married female employment rates over time which is highest for the Netherlands and Spain (about 8 percentage points). On average, employment rates are higher in Denmark, France, Germany, and the U.K. (between 65\%-70\%), and lower in the Netherlands, Italy (around $50 \%$ ), and Spain (40\%). To look at the effect of selecting on married women, with husband continuously employed, we can compare these figures to official figures from EuroStat. The positive trend and the average employment differences are similar with the

\footnotetext{
${ }^{3}$ We evaluate the sensitivity of our results to conditioning on husband's employment in section 5. For a detailed description of the sample selection see appendix A1.

${ }^{4} \mathrm{We}$ also evaluate the sensitivity of our results to this definition in section 5 .
} 
ones observed in the first two columns of Table 1 which shows employment rate of females aged $24-55$ years old. ${ }^{5}$

Table 2 presents employment rates stratified by education level and by the presence of kids in the household. Education is defined using the (ISCED) classification. We observe that in all countries those with higher education are more likely to be employed. Quite clearly, independently of the presence of kids, the difference in employment rates across education levels (the education "gradient") is higher in the Netherlands, Italy, and Spain, countries where participation of married women is low over this period. It turns out that the cross-country differences in employment appear to be larger for lower educated women than for higher educated as can be seen for Italy and Spain compared to the U.K. or France for example. This suggests that part of the explanation for the differences in employment rate can be due not only to differences in the average education level (the average education level is lower in the South) but also due to the segmentation of the labor market along education levels (the education gradient), with those in low levels having a harder time to find jobs in southern countries.

Although descriptive, Table 2 makes another important point. The effect of motherhood, as measured by the difference in employment rate by the presence of kids, cannot explain low employment in the South. It suggests that the presence of kids lowers employment rates to a larger extent in France, Germany, the U.K., and Denmark, countries which have higher employment rates on average, compared to Italy, and Spain. If motherhood penalties explained employment rate differences across countries, then we would expect larger differences in employment between women with and without kids in countries with low employment rates. This is not what we observe from Table 2. What differs most is the employment rate of females without kids. Of course, many confounders may be present that do not enable to infer from the difference in employment rates across groups, the true causal effect of motherhood.

For example, reverse causality from employment prospect to fertility obscures such comparisons. In countries with high true and perceived motherhood penalties (e.g. low provision of childcare), it may be that women who give birth are quite different from

\footnotetext{
${ }^{5}$ The Eurostat figures are from cross-sectional labor force surveys and not from a panel study. Furthermore, it refers to a population which is slightly different from the population considered here, both in terms of age, marital status and employment status of the husband.
} 
those who do not give birth. They may be able to combine work and motherhood more easily because they have the resources to do so (both in terms of informal childcare but also financial resources to buy formal childcare). This can explain why little difference in employment rates is observed between females with and without kids in a country like Italy. But it cannot explain why females without kids have much lower employment rates than in Northern countries. To verify this possibility we can look at the extent of the "time-crunch" mothers face across countries when deciding between childcare and work. Since the ECHP does not have information on time use, we turn to another dataset, the Multinational Time Use Study (MTUS).

Table 3 shows data on time use obtained from the Multinational Time Use Study (MTUS). We use micro-data from 1995 in the U.K. and the Netherlands, 1998 in France, 1992 in Germany and 1989 in Italy. ${ }^{6}$ We distinguish between time spent on market, childcare, and home production and select diaries filled for weekdays. The categories make a clear distinction between time spent doing home production for children and other home production. Focusing on childcare, Italy has the lowest number of hours spent per day on childcare (1.56 vs. 1.09 hour per day for non-working and working mothers respectively). Moreover, in France, Germany, and the U.K., non-working women spend about $55 \%$ more time in childcare compared to working ones, while this increase is about $40 \%$ in Italy, and $25 \%$ in the Netherlands. In absolute terms, the difference in Italy is roughly 30 minutes compared to more than an hour in Germany and the U.K. Regarding time spent on home production (which excludes activities directly related to children), non-working women's time is higher compared to working ones by a factor of 1.8 in France, 1.6 in Italy and Germany, by only 1.3 in the Netherlands and 1.4 in the U.K.

\footnotetext{
${ }^{6}$ The MTUS contains harmonized aggregated time spent per day in 41 categories as well as a limited set of characteristics that can be exploited. We selected married or cohabiting females aged 20 to 45 that are not in school and who have kids under the age of 16 years old. We also selected on diaries reported during weekdays or week average. We define time spent on work as time spent traveling to work, working outside and at home, on a second job. Time spent doing home production includes time cooking, washing up, spent doing housework, doing odd jobs, gardening and shopping. Finally time spent in child care includes feeding and food preparation for children, washing, changing babies, putting children to bed and getting them up, babysitting, other care to babies, medical care for children, reading or playing with children, helping children with home work and supervising children. Appendix A2 gives more detail on the construction of the dataset used for this table. There is no data for Spain and only data from 1964 for Denmark in the version we used.
} 
Non-working females tend to spend the same amount of time on home production whether they have children or not.

These statistics indicate some substitution of market time for childcare in countries such as France, Germany, and the U.K., but does not reveal a large "time crunch" for Italian women with children. This tends to support the reverse causality hypothesis. Italian women who decide to have children might be more likely to have informal arrangements to take care of children. This can explain why there is little difference in employment rates between those who have children and those that don't even if motherhood penalties may be high, but cannot explain the remaining employment rate differences across countries. High perceived (and real) motherhood penalties might discourage females to have children in the first place. ${ }^{7}$

Indeed, over recent decades, the negative correlation that appeared between fertility and employment at the country level seem to have switched sign from negative to positive (Ahn and Mira, 2002). The evolution of policies aimed to ease motherhood penalties has been far different across countries. Countries in which high fertility is associated with high employment (mostly in the north) have implemented public childcare systems (or subsidized private ones, maternity and paternity leaves) and others introduced child benefit provisions during the $80 \mathrm{~s}$ and $90 \mathrm{~s}$.

Differences in childcare institutions and child benefit policies are potentially associated with the variation in employment rates. But although the effect of both types of measures on fertility is probably non-negative, the effect of both on employment may work in opposite directions. While the existence of childcare may help women combine work and childbearing, child benefits may give the opposite incentive through an income effect. Table 4 contains a brief description of child benefits, maternity leave and childcare that was in effect during the time of the panel (1994-2001). In countries such as France and Germany there is provision for a birth grant, more generous in Germany, and lasts for 2 and 3 years, respectively. In Denmark a birth grant is available only for women who give birth to more than one child, while in the U.K. is a limited lump-sum payment. In

\footnotetext{
${ }^{7}$ In relatvie terms we do find that non-working women in Italy spend more time on childcare compared to | working ones, which is consistent with the findings by Galdeano and Ichino (2005). However, in absolute terms the difference is small to explain the remaining employment rate differences between females working and those not working.
} 
addition, there is a family allowance which depends on the number of kids in the family (France, Germany), or is paid for each child (Denmark, Netherlands, Spain, UK), and the amount may vary according to the age of the child (Denmark, Netherlands). In France, families are eligible only from the second child onwards and the amount can be up to 632 Euros per month.

This helps reconcile why in countries with generous benefit packages such as France and Germany, high employment rates are compatible with large cross-sectional differences in employment rates of those with and without kids. However, in the U.K., a country with very limited benefits, females without kids work more than those with kids. We show later that mothers in the U.K. come back rather quickly to the labor force after having a child, compared to other countries.

\subsection{Persistence}

Table 5 presents statistics on labour market transitions in the sample. In the second column we report a measure of persistence proposed by Shorrocks (1978). ${ }^{8}$ Countries with low employment rates tend to exhibit more persistence (Italy, Spain) while countries with less persistence (Germany, U.K.) have higher employment rates. Columns 2 and 3 show also that a lower percentage of non-workers at time t-1 in Italy and Spain become workers at time t. The last four columns present the frequency of the number of transitions for females in each country. In Italy, about $75 \%$ of women do not experience any transition in their labor market status. In Spain and France too, only about $28 \%$ of women experience a transition. Finally, in the Netherlands, Germany and the UK the share of women in the sample who do not change status is much lower (63\% for NL, and about 58\% for GER and UK). Particularly in the U.K. and in Germany, there are respectively $12.9 \%$ and $15.2 \%$ of women making 2 transitions in the 8 years period of the panel. These transitions can be due to a multitude of factors, such as births, but persistence can also be linked to characteristics of the labor market such as search frictions.

\footnotetext{
${ }^{8}$ For a state-space with $\mathrm{S}$ states, we can construct an index of mobility as $\left.[\mathrm{S}-\operatorname{tr}(\mathrm{P})] /(\mathrm{S}-1)\right]$ where $\mathrm{P}$ is the estimated transition matrix If there are no transition $\operatorname{tr}(\mathrm{P})=2$ and the index is 0 . At the other extreme, if there is no persistence and $\mathrm{P}$ is a matrix with $1 / 2$ probabilities of exiting to the other state, then mobility is 1 .
} 
In fact, there is a lot of persistence in employment outcomes, more so in countries where the employment rate is the lowest (Spain and Italy). Therefore, similar to the argument of Layard et al. (1991) for the U.S. - European difference in unemployment rates, persistence can potentially explain differences within Europe with respect to employment rates of women. Azmat et.al. (2004) show that in Mediterranean countries (Italy, Spain, France) there is also a gender gap in unemployment rates associated with differences in transition rates between unemployment and employment. In particular, females are more likely to exit from employment to unemployment and less likely to enter from unemployment to employment compared to males. Therefore, it seems that countries which exhibit high persistence in employment patterns are those with low employment.

This finding serves as a motivation to think about a model that investigates the sources of this persistence in order to explain the cross-country variation in employment rates. This also helps to think of the intertemporal effect of motherhood on employment and how demand and social norms come into play.

\section{Frictions and Persistence in Female Labor Supply}

In theory, Garibaldi and Wasmer (2004) show that frictions have both a positive exit and a negative entry effect on the employment rate. The level of female employment is determined by a number of factors which involve both demand and supply. Institutions shape financial constraints and opportunities available to mothers while the availability of jobs for various skill groups depends largely on the state of labor demand in the economy, how female employment is perceived and the degree of frictions in the labor market. Some institutions, such as those helping mothers with kids to accommodate work and childcare, interact with the more traditional frictions associated with searching for jobs. On the one hand, high transition costs can imply that mothers have difficulties reintegrating the labor market after giving birth. But it can also mean that they may not exit the labor force in the first place. In addition to transition costs, skill obsolescence and loss of returns to experience due to labor force withdrawal are important factors in the decision of married women to temporarily exit employment. The positive effect of 
frictions on employment can be stronger if childcare institutions are in place, or if maternity leave arrangements guarantee a job back after a certain period of inactivity. Hence, it is unclear what effect frictions have on aggregate employment rates.

Assume similarly to Hyslop (1999) and Garibaldi and Wasmer (2004) that a married woman makes a decision every period $t$, to work in the market (work for pay) $\left(y_{t}=1\right)$ or stay at home and produce some goods at home $\left(y_{t}=0\right) .^{9}$ These activities are rewarded at a rate $w_{t}$ and $a_{t}$ for market and non-market work respectively, and she has access to non-labor income $m_{t}$ which includes the husband's income. ${ }^{10}$ One can see $a_{t}$ as the net home production that can be consumed by using one unit of time. The reward from such decision takes the form of a well-behaved utility function (increasing and concave) $u\left(c_{t}, x_{t}\right)$ where $x_{t}$ are preference shifters. ${ }^{11}$ In addition to standard demographic factors (such as the presence of kids, education, age) social norms can enter preferences by shaping women's view about the utility to be derived from work. In making decisions today, she discounts future utility from her actions at a rate $\rho$ and we assume she has an infinite life horizon. She has beliefs about future states of the world (income, value of home production and taste shifters) summarized by the expectation operator $E_{t}$. Present discounted utility is given by

$$
U_{t}=E_{t} \sum_{s=0}^{\infty} \rho^{s} u\left(c_{t+s}, x_{t+s}\right)
$$

\footnotetext{
${ }^{9}$ We do not consider leisure because we did not witness clear differences across countries in the total amount of time devoted to childcare, home production and market work (except perhaps in the Netherlands). This suggest that time devoted to leisure is constant across countries. Freeman and Schettkat (2002) reach a similar conclusion when looking at German vs. U.S. differences. We also focus on employment defined as working more than $15 \mathrm{hrs}$ a week. We do this since most of the variability across countries is observed at this margin and has been found most responsive to institutions, at least in the U.S. (Heckman, 1993).

${ }^{10}$ Joint decision making is relevant when modeling female labor supply. In the data we use, we condition on the husband working full-time so as to avoid having to deal with the simultaneity in transitions in and out of the labor force. In the econometric application, we also relax the assumption that the husband's income is strictly exogeneous and allow for a time-invariant correlation between preferences and opportunity set of both spouses.

${ }^{11}$ Taste shifters can include both demographic characteristics such as age and education but also presence of children. Of course, fertility is a choice variable but we abstract from that dimension in the theoretical model in order to emphasize how persistence interacts with the equilibrium rate of employment. Allowing fertility to be endogeneous would not change the qualitative implication of the result shown here. In the econometric model, we relax the strict exogeneity assumption of fertility in a way similar to Hyslop (1999).
} 
We assume for simplicity that she does not have the possibility of saving and therefore faces the following constraint in each period: ${ }^{12}$

$$
c_{t}=m_{t}+\left(w_{t}-\gamma\left(1-y_{t-1}\right)\right) y_{t}+\left(1-y_{t}\right) a_{t}
$$

Persistence is introduced as a search friction decreasing the reward from market work for those out of the labor force. ${ }^{13}$ This friction can also be interpreted as the reduction in wage that a returning female to the labor market will be offered. From an ex ante perspective, a working female will take into account the potential drop in wage she must accept to return to the labor market upon deciding to exit today. Under stationarity, the value function in period $t$ only depends on the immediate past employment state and given by $V\left(y_{t-1}\right)=\max \left(V^{1}\left(y_{t-1}\right), V^{0}\left(y_{t-1}\right)\right)$, where superscript 1 and 0 denote market work and non-market work respectively in period $t$. Because there is no uncertainty associated with the search process, the reservation wage $w_{t}^{*}\left(y_{t-1}\right)$ is given by $w_{t}^{*}(1)=w_{t}^{*}(0)-\gamma$.

The reservation wage is adjusted for the compensation required for the transition cost incurred when out of the labor force at $t-1$. In the absence of transition costs $(\gamma=0)$, the reservation wage $w_{t}^{*}$ is independent of past labor force status. When costs are positive, we get the inequality $w_{t}^{*}(1)<w_{t}^{*}<w_{t}^{*}(0)$, i.e. there is a wedge created in reservation wages. The reservation wage when working in the last period $w_{t}^{*}(1)$ is lower because workers face higher future costs from exiting the labor force and coming back to the labor force.

Aggregate implications are easy to characterize. First, we derive the employment decision rule based on the reservation wage and a given wage offer $w_{t}$. The employment decision rule is given by

$$
y_{t}=I\left(w_{t}^{*}(q)-w_{t 0}^{*}+\gamma y_{t-1}>0\right)
$$

where $w_{t}^{*}(q)=w_{t}-w_{t}^{*}, w_{t 0}^{*}=w_{t}^{*}(0)-w_{t}^{*}$, and $q=(x, m, a)$ denotes current but also expected values of $q$. Hence, the decision rule is a dynamic binary choice model. In the

\footnotetext{
12 Allowing for liquidity constraints does not affect the results but complicates (unnecessarily) the exposition. On the other hand, if savings are unconstrained, transition costs would not affect employment decisions.

${ }^{13}$ This cost is assumed to be first-order markovian such that it does not depend on the length of time spent out of the labor force. A more general model would allow for such duration dependence effect. We only consider first order state (or occurrence) dependence in this paper.
} 
case where $\gamma=0$, equation (4) collapses to the standard reservation wage model where the worker compares the wage offer with his reservation wage $w_{t}^{*}$ which is a function of $q$. When costs are positive, the term $w_{t 0}^{*}$ captures the increase in the reservation wage of non-workers due to transition costs, while the second term $\gamma y_{t-1}$ captures the difference in reservation wages between non-workers and workers at time $t-1$. From the law of motion of employment, the equilibrium employment rate is given by

$$
\bar{e}=\frac{1-G\left(w_{t 0}^{*}\right)}{1-G\left(w_{t 0}^{*}\right)+G\left(w_{t 1}^{*}\right)}
$$

where $G()$ is the cumulative distribution of $w_{t}^{*}(q)$ in the population, and $w_{t 1}^{*}=w_{t}^{*}(1)-w_{t}^{*}$. As $\gamma$ increase, there are less females entering the labor force $\left(G\left(w_{t 0}^{*}\right)\right.$ increases), while there are also more women staying in the labor force $\left(G\left(w_{t 1}^{*}\right)\right.$ decreases $)$

Hence the aggregate effect depends on the shape of the distribution $G$. If the density of workers at the entry margin is greater than that at the exit margin, then increasing transition costs lowers the employment rate. Alternatively, if there are more females willing to stay in the labor force because of fear of facing transition costs when out, then the effect on employment is positive. For cross-country comparisons, this implies that even with high transition costs, it is possible that employment is higher than in another country with lower transition costs. That will occur if the stationary distribution of characteristics in the population is skewed towards higher employability types or labor demand is higher in segments of the market which hire high employability types. Hence, from an econometric perspective, it is important to relax parametric assumption on the distribution of unobserved heterogeneity.

Although simple, such a model highlights that both supply (factors affecting reservation wages) as well as demand (through wage offers and transition costs) are likely to affect employment in Europe and explain cross-country differences. If there is low demand for some type of workers, this will inevitably decrease wage offers and employment rates for that group. Low employment among low skilled females in Southern Europe can be due to the lack of jobs or unfavourable pay conditions. It is not necessarily the case that supply factors are the sole factors driving such differences. 
Social norms can affect both demand and supply by shaping attitudes of women and employers about the desirability of hiring women over men. These norms can be different across groups in the population and industries. Hence, it creates heterogeneity, most often unobserved, in employment patterns.

On the other hand, search frictions can amplify the effect of motherhood penalties, by lengthening the period out of the labor force, while they can also give incentives for many females not to exit the labor force because it is hard to come back to a similar job or to a similar wage. Such frictions can differ by skill groups. For example, it could be that search frictions are higher in Southern Europe or for low skill groups. It can also be that motherhood penalties are larger for these groups as well as they may have less resources available to "buy out" their time in childcare. We also consider than possibility in section 5 .

\section{The Econometric Model}

\subsection{Dynamic Equation}

We define an indicator $y_{i t}$ if respondent $i$ reports being usually employed more than 15 hours a week $(=1$, else 0$)$ in year $t$. We observe this indicator and other relevant characteristics $x_{i t}$ for $T$ consecutive years. We specify equation (4) as

$$
\begin{aligned}
& y_{i t}=I\left(x_{i t} \beta+\gamma y_{i t-1}+u_{i t}>0\right) \\
& t=1, \ldots, T-1
\end{aligned}
$$

The unobservable term $u_{i t}$ is decomposed into a time-invariant term, $\alpha_{i}$, and a timevariant term $\varepsilon_{i t}$. We first assume this last term is iid normal and that $x_{i t}$ is strictly exogenous with respect to this unobservable (conditional on $\alpha_{i}$ ). We leave $\alpha_{i}$ unspecified for now and postpone treatment of unobserved heterogeneity to the next section.

The interpretation of $\gamma$ in statistical terms has a long history in econometrics and is widely applied in microeconometrics (see Heckman and Willis, 1977). It is usually referred to as the parameter capturing true state-dependence (as opposed to spurious 
state-dependence). It captures a dependence of the employment decision, irrespective of unobserved heterogeneity $\left(\alpha_{i}\right)$, on past employment decisions. In contrast, heterogeneity creates persistence because of self-selection of those with high employability in market work and those with low employability in non-employment. Hence, mean differences in employment rates are observed across the two groups without there being a causal effect of employment state on future employment.

The issue of distinguishing state-dependence (or frictions) from heterogeneity is not merely a statistical one. It does point to what might be likely to increase female employment. In the case where heterogeneity is the prime driver of persistence, an analysis of what drives this heterogeneity may be informative about what groups from the population governments should target to increase employment. As we shown in section 3, such results would also illustrate the danger of prematurely concluding from the association between persistence and employment that reducing frictions is likely to increase female employment. It might be that reducing frictions would reduce employment, if the exit effect is stronger than the entry effect.

\subsection{Identification of Dynamics}

Longitudinal data with at least three repeated observations is necessary to distinguish true from spurious dependence under the assumption that $x$ is strictly exogeneous with respect to $\alpha_{i}$ (Heckman, 1981). ${ }^{14}$ Unless the $x$ process varies over time, the identification of $\gamma$ relies on functional form. Several characteristics included in $x$ will vary over time, such as the births, non-labor income and health (see section 4.2).

We specify the effect of childbearing in a dynamic way as well. We allow for different effects on the "stock" of kids aged 1-3, 4-6, 7-12 and 13-18 as in Hyslop (1999)

\footnotetext{
${ }^{14}$ In a setting without regressors, Chamberlain (1984) shows that $\gamma$ can be identified from 4 observations without restricting $\alpha_{i}$. This leads to conditional logit formulation comparing sequences ending and beginning in the same state but where intermediate states are used to identify positive from negative state dependence. In a setup with regressors, Honoré and Kyriazidou (2000) use a similar strategy but need to restrict substantially how $x$ changes over time to identify $\gamma$. In the non-linear fixed-effect setting, the incidental parameter problem remains problematic. Carro (2003) proposes a bias reduction method in the fixed effect setting.
} 
but also allow for separate effects of births on employment outcomes. The age categories used are broadly in-line with childcare institutions and schooling across countries (e.g. see Table 4) . A birth is disruptive in many respects and its effect potentially differs from that of having children aged 1-3 years old. Furthermore, we make a distinction between $1^{\text {st }}$ and second (and more) births. This allows capturing dynamic employment effects of first and second births as children age and transit into different stock variables. Since the model includes state-dependence as well, birth effects can be persistent and this effect is separately identified from that of childbearing at young ages.

\subsection{Heterogeneity}

In general, one might suspect that $\alpha$ is not independent of the number of children in the household. Females might decide to have children because they have few career prospects. They may also decide to have children because they have other family members that can take care of child while working... The same endogeneity problem probably holds true for the inclusion of the husband's income. But conditional on the fertility history, or the average income of the husband over time, the remaining variation (such as the exact occurrence of births or deviations in non-labor income) is arguably less likely to depend on $\alpha$. This quasi-fixed effect approach was first suggested by Mundlack (1978). Similarly to Hyslop (1999), we adopt the following specification for unobserved heterogeneity

$$
\alpha_{i}=\sum_{s=0} \delta_{s} k_{i s}+\sum_{s=0} \vartheta_{s} m_{i s}+\eta_{i}
$$

where $k_{i s}$ and $m_{i s}$ are the number of kids and non-labor income in period $s$ respectively. The remaining unobservable $\eta_{i}$ is assumed independent of other regressors in $x$. Since these include births, number of kids and non-labor income, such effects are by construction independent of $\eta_{i}{ }^{15}$

In the case of children and non-labor income, the strict exogeneity assumption of those variables with respect to $\varepsilon$ still needs to be made to identify their causal effect on

\footnotetext{
${ }^{15}$ For other regressors, particularly those time-invariant, a specification like (7) makes clear that causal effects cannot be separately identified from parameters in the specification of unobserved heterogeneity unless we make a strict exogeneity assumption on the joint distribution of heterogeneity and characteristics.
} 
employment probabilities. Since we condition on the husband working full-time, it seems more plausible to assume that there is no contemporaneous adjustment from husbands at the intensive margin because their wife has made a transition at the extensive margin. ${ }^{16}$

As for fertility and children variables, Hyslop (1999) finds in the U.S. small and insignificant effects of birth next year on employment outcomes in the current year suggesting that anticipation effects or other contemporaneous simultaneity problems are likely to be marginal in the analysis. Much of the endogeneity, if present, is likely to be caused by common time-invariant factors accounted for in the quasi-fixed effect strategy.

Based on the discussion in section 3, we do not impose a distributional assumption on $\eta_{i}$. This allows for the distribution to be asymmetric and potentially help understand why there is a positive correlation between persistence and employment rates across countries as seen in Table 5. We adopt the widely used Heckman and Singer (1984) point-mass approach. We assume that the distribution of $\eta_{i}$ has $K$ points of support $\eta_{k}, k=1, \ldots, K$ with associated mass probability $p_{k}=\operatorname{Pr}\left(\eta_{i}=\eta_{k}\right)$. Since the probit model is identified up to scale we fix $\operatorname{var}\left(\varepsilon_{i t}\right)=1$ and in addition fix $\eta_{1}=0$. We found 3 points of support in the analysis for each country. Results remained very similar when considering 4 points of support. ${ }^{17}$

\subsection{Initial Conditions and Estimation}

Since the whole history of $y$ is not observed, the initial observation $y_{i 0}$ is potentially correlated with $\eta_{i}$ such that integrating over the marginal distribution of this heterogeneity term will yield inconsistent estimates. This is known as the initial condition problem (Heckman, 1981). The probability we wish to know is

$$
\operatorname{Pr}\left(y_{i 1}, . ., y_{i T-1} \mid x_{i}\right)=\int\left(\prod_{t=1}^{T-1} \Phi\left(y_{i t}, x_{i t}, z_{i}, \eta_{i} ; \theta_{1}\right)\right) d F\left(\eta_{i}, y_{i 0} \mid x_{i}\right)
$$

\footnotetext{
${ }^{16}$ In the application, we restrict the $\vartheta_{s}=\vartheta$ and use time means of non-labor income to minimize the number of parameters used in estimation. It turns out that such restriction was not rejected from the data based on simple likelihood ratio tests. Although jointly different from zero in some countries, there are very few individual coefficients that were statistically significant.

${ }^{17}$ Both Akaike Information Criterion $(-2 \ln L+2 q)$, where $q$ is the number of parameters and $\ln L$ is the $\log$ likelihood, as well as the Bayesian Information Criterion $(-2 \ln L+(\operatorname{lnN}) q)$ were minimized at 3 points of support. Only in Spain, was it minimized at 4 with very little differences in the point estimates. Results of those tests available upon request.
} 
but we miss information on the joint distribution of $\eta_{i}$ and $y_{i 0}, F\left(\eta_{i}, y_{i 0} \mid x_{i}\right)$. The probability $\Phi\left(y_{i t}, x_{i t}, z_{i}, \eta_{i} ; \theta_{1}\right)$ is the standard normal CDF with parameter vector $\theta_{1}$. The most widely used "solution" is proposed by Heckman (1981). We can decompose $F\left(\eta_{i}, y_{i 0} \mid x_{i}\right)$ as the product of a conditional probability $\operatorname{Pr}\left(y_{i 0} \mid x_{i}, \eta_{i}\right)$ and the marginal probability for $\eta_{i}$.

The conditional probability can be specified as a "reduced-form" solution substituting backward,

$$
\operatorname{Pr}\left(y_{i 0} \mid x_{i 0}, \eta_{i}\right)=\Phi\left(y_{i 0}, x_{i 0}, \eta_{i} \mid \theta_{0}\right)
$$

where this equation does not share parameters with the first equation but includes $\eta_{i}$ (and $y_{i 0}$ ) the initial condition equation is informative for estimation of the dynamic equation. The last step is to integrate over the marginal distribution of $\eta_{i}$.

From equation (8), Wooldridge (2005) proposed assuming instead that $E\left(\eta_{i} \mid y_{i 0}\right)=\psi y_{i 0}$ in the quasi-fixed effect setting we have already adopted. This conditional likelihood approach does not appear to impose stronger assumptions that what is assumed in (9). Hence, another approach is to simply condition the index in $\Phi\left(y_{i t}, x_{i t}, z_{i}, \eta_{i} ; \theta_{1}\right)$ on $y_{i 0}$, perform the required integration over the distribution of $\eta_{i}^{*}=\eta_{i}-E\left(\eta_{i} \mid y_{i 0}\right)$ and maximize the conditional likelihood.

Since no method has a clear advantage over the other, we will apply both and compare the resulting estimates in terms of average partial effects. ${ }^{18}$ One particular issue that appears problematic at first sight is how to handle the conditioning on $y_{i 0}$ in the Wooldridge case when computing average partial effects. However, in the large sample case, the average partial effects do not depend on the distribution of $y_{i 0}$ because it is average out. In small sample, this may be more of a problem. The model is estimated using maximum likelihood (BFGS numerical optimization) and standard errors computed using the inverse Hessian at estimated parameters.

\footnotetext{
${ }^{18}$ See Chay and Hyslop (2000) for a comparison of initial condition solution methods.
} 


\section{The Results}

\subsection{Dynamic Binary Choice Model Estimates}

Table 6 and 7 present estimates of the dynamic models using two solutions for the initial condition problem (Wooldridge (2005) and Heckman (1981)). We focus our discussion of the results on those using the Wooldridge solution because results are relatively similar across the two methods. We discuss differences when they occur. Both methods make different assumptions and hence variability in results is an indication that such models are sensitive to how initial conditions are dealt with. We will refer to results using the Wooldridge solution by WS and those using the Heckman solution by HS. Results are presented in the form of average partial effects since each country's employment latent process is identified up to scale. ${ }^{19}$

Mirroring descriptive statistics in Table 2, employment rates differ considerably across education groups and those differences tend to be larger in countries such as Italy, Spain and the Netherlands, countries with lower employment of married women. For example, Italian women with college education have 18.2 p.p. higher employment probability than those with low education. The conditioning on children and the husband's income reduces those differences but they are still considerable. We shall explore further if such differences capture parameter heterogeneity or the poor employment prospects of low educated in Southern Europe.

In most countries, except in Italy, Spain and Denmark, we can reject the hypothesis that long-term labor supply behavior of women is not negatively related to permanent income of the husband. Based on the discussion in Section 4, it is difficult to say if this rejection is due to a correlation in preferences or other factors, or to a true

\footnotetext{
${ }^{19}$ We compute for each respondent, the derivative of the employment probability with respect to each covariate (finite difference for discrete covariates). This is done for each point of the discrete heterogeneity distribution. The derivative is then weighted using probability estimates for each point and then averaged over all respondents to provide an average partial effect (see Wooldridge, 2005). Standard errors are calculated by simulation from the estimated asymptotic distribution of the parameters.
} 
causal effect of permanent income. Panel data is silent on that possibility since permanent income, by definition, does not vary over time. Perhaps, a more convincing source of identification for the effect of income is to look at how transitory income is related to transitions in-and-out of employment for wives. Estimates in Table 6 show some effect, significant at the $10 \%$ level, in Italy (-9.0 p.p per hundred thousand euros in yearly income). A larger effect is found in Germany (-18.4 p.p). This is consistent with the institutional setting in Germany in which the tax system benefits one-earner families. Marginal tax rates for the second earner are relatively higher than in any other European country (OECD, 2003). This rate was $57 \%$ in 2000 compared to $30-40 \%$ in other countries. In particular, due to joint taxation, an increase of husband's income, which increases household income, reduces the splitting advantage that the joint taxation system provides (Gustafsson, 1992). ${ }^{20}$

The results for the husband income effect differ to some extent depending on which initial condition solution we use. The null of no association with permanent income is not rejected in Italy when using the WS, while it is rejected when using the HS. On the other hand, association is rejected in France using WS while not using HS. One potential explanation is that when using the WS we explicitly condition on initial employment. Hence, the association of heterogeneity with husband's income in the quasifixed effect formulation (eq. (7)) can be absorbed or confounded by the initial condition. However, both effects related to transitory income are quite similar across methods and statistically significant in Italy and Germany.

Table 6 estimates reveal considerable differences across countries in the size of birth effects but also their timing. The contemporaneous effect of first birth is large in the Netherlands, France and the U.K. (order of 20\%) while it is much lower in Denmark and Spain and relatively small in Italy. Effects of second births are of smaller magnitude in general although statistically significant in several countries. The timing of the effect varies considerably across countries. The effect of having kids in young age (1-4) is the largest in Germany, followed by the Netherlands. In all other countries, effects of the "stock" of kids are relatively smaller. In Germany, the U.K. and Netherlands, we can

\footnotetext{
${ }^{20}$ Results were qualitatively similar when we did not restrict the sample to couples where the husband was continuously employed. Results available upon request.
} 
reject the null that children are strictly exogenous. Likelihood ratio tests on the joint significance of the quasi-fixed effects, the number of children for each year (see eq. 7), yield values of $13.83,25.54,32.73$, (compared to critical value $\chi_{(8)}^{2}=15.5$ at $5 \%$ level) for Germany, U.K. and Netherlands, respectively.

The dynamic effect of fertility cannot be evaluated without looking at the statedependence effect which works as a potential multiplier for any contemporaneous effect of covariates on employment probabilities. Table 5 showed that aggregate persistence correlates positively with employment rates. But results from both Table 6 and 7 show that this is not due to state-dependence. First, differences across countries in the statedependence effect are not that large except for France. State-dependence effects are estimated around 30\% which is quite similar in magnitude to the effect found by Hyslop (1999) in the U.S. Based on results from Table 6, state-dependence is lowest in Spain, Italy and Denmark and largest in France. However, aggregate persistence is largest in Italy and Spain. Hence, state-dependence cannot explain the correlation between employment rates and persistence.

On the other hand, the relative importance of unobserved heterogeneity (relative to the unit variance of the transitory error term) is larger in Italy, Spain and Denmark, while lowest in the U.K. and France. The share of the variance of the total error term (transitory + heterogeneity) is largest in Spain and Italy $(76.9 \%$ and $76.0 \%$ respectively). ${ }^{21}$ Hence, it is more likely that the shape of the wage distribution and reservation wages explain the correlation between employment rates and persistence across these countries. For example, the Italian distribution of unobserved heterogeneity is estimated skewed left (the lowest point has probability 0.233 compared to 0.149 for the high point) which adds to the large differences in employment probabilities across skill groups. In the U.K., the distribution of heterogeneity appears to be skewed right, towards high employment probabilities.

\footnotetext{
${ }^{21}$ To calculate this number, we note that the variance of unobserved heterogeneity can be calculated from the point-mass estimates and their probability. Denote this variance by $\sigma_{\eta}$. Since we normalized the variance of $\varepsilon$ to one for identification, $\rho=\sigma_{\eta}\left(1+\sigma_{\eta}\right)^{-1}$ gives an indication of the relative importance of unobserved heterogeneity in the total variance of unexplained employment variation.
} 
In most countries, state-dependence effects are relatively insensitive to which initial condition solution is used. Two exceptions should be noted. Both involve countries with high persistence, Italy and Denmark. Although the difference in Italy is not large (0.234 with WS compared with 0.296 with HS), it still remains that when (aggregate) persistence is high, estimates of state-dependence effects might be more sensitive to which solution is used. The Danish estimate is far different depending on whether we use the Heckman solution (0.385) compared to 0.188 when using the WS. In addition to persistence, the Danish sample is rather small for the estimation of such models (423 observations). This illustrates that although both methods yield similar results in most instances, in an extreme situation where the sample size is small and/or persistence is high, results may be quite sensitive to the initial condition solution used.

\subsection{The Dynamic Effect of Motherhood on Employment}

Effects of children are found to be quite different across countries both in their magnitude and their timing. Since state-dependence also helps "propagate" such effects, it is interesting to look at the simulated dynamic effect of a birth on the employment of mothers. We know from the previous discussion that this cannot explain low employment in Southern Europe. However, it may help understand the interaction between employment and childcare \& child benefit institutions.

We consider a married woman with average characteristics in each country. We then simulate the effect of a first birth over time compared to a baseline scenario. The effect of the birth is contemporaneous in the birth year. The following year, its effect is transported both through the stock variable (one kid is added to the stock of kids aged 03) and the potential effect trough the lagged employment state (state-dependence), if such effect affected the employment decision in the year of the birth. We do the same when the kid becomes 4, in which case the stock of kids aged 4-6 is augmented and the stock of 0-3 is depleted by one. We simulate this effect 5000 times allowing for different random shocks. Furthermore, we average employment rates over the estimated heterogeneity distribution using both point estimates and probability estimates. Figure 1 shows the 
difference in the employment probability (compared to baseline, i.e. the motherhood penalty).

The dynamic pattern of the "motherhood employment penalty" is quite different across countries. We can separate countries in three groups. First, there is Italy were very little effect is observed, both contemporaneously and in the years following birth. Second, there is a group of countries composed of Spain, Denmark and the U.K. that have larger contemporaneous effects but quick recovery compared to the third group composed of France, Germany and Netherlands. In particular, effects of a first birth on the probability to work more than 15 hrs per week are large and persistent in France and the Netherlands where it remains at 20 percentage points after 8 years. In the case of Germany, the absence of a contemporaneous effect can be due to the way employment is reported in the ECHP. Indeed, respondents are asked about their current labor force status, which classifies as employed, respondents that have a job but are temporarily out. This may lead to misclassification of those on maternity leave. This misclassification can be stronger because take up of maternity leaves are quite frequent in Germany.

The strong persistent effects in the Netherlands and Germany may be confounding irregular part-time work (less than $15 \mathrm{hrs}$ a week) with non-participation. Indeed, Table 8 shows that there is a much larger share of irregular part-time work in Germany, the Netherlands, but also the U.K. If we define employment as working more than $1 \mathrm{hr}$ a week instead of 15, Table 9 reveals that in low and medium educated groups, the share of such low part-time work is higher than for high educated. However, except in the U.K., the share of women working part-time does not appear to depend on the presence of young children. This may be misleading since confounding effects may be present. Hence, we re-estimate the same dynamic model as in Table 6 using a definition of work as working more than $1 \mathrm{hr}$ per week and redo the simulation exercise in Figure $1 .^{22}$ Figure 2 shows that for the Netherlands, births affect strongly the probability to work more than $15 \mathrm{hrs}$ a week but much less the probability to work fewer than $15 \mathrm{hrs}$. The difference is large and suggests that part-time work (were part-time really means less than 2 full days a week) is a popular channel for coming back to the labor force. The parttime distinction was not a factor in the dynamic effect found for Germany.

\footnotetext{
${ }^{22}$ The estimation results are available from the authors upon request.
} 


\subsection{Heterogeneity Effects across Education Groups}

Since conditional employment rates are quite different across education groups in countries with relatively low female employment, one may conjecture that this hides heterogeneity in the effect of some covariates by level of education. Since the negative effect of children is pronounced in most countries, we re-estimated models in Table 6 allowing the effect of birth, and the number of children in each age group, to vary by education level. Table 10 gives average partial effects as well as a likelihood ratio test on the equality of the underlying parameters on the latent index $(\beta)$ across education groups.

It turns out that very little differences are observed. The test only rejects equality of the parameters in Italy, the U.K., and Denmark (at 10\%). For Italy, the contemporaneous effect of a birth found in Table 6 appears to be driven by the low educated. However, the difference is so small that it cannot explain aggregate differences across education groups. For the UK, and Denmark, the stock effect appears to be driven mostly by high educated females. We also considered allowing for different statedependence effects by level of education. This yielded a similar conclusion that parameter heterogeneity is not behind differences in employment across education groups in Southern European countries. Hence, we conclude that the education gradient is due to other factors, potentially related to the demand side of the market or social norms.

\subsection{Regional Trends in Employment, Demand and Social Norms}

Our main conclusion from the preceding analysis is that female employment differences across countries, which are pronounced for the low educated, cannot be explained by differences in the effect of motherhood or search frictions. In this section we attempt to provide some explanations for these differences focusing on the regional dimension. ${ }^{23}$ Table 11 shows female employment rates by region and by education level in 1994 and 2001 for Italy and Spain. Focusing on total employment by region, we

\footnotetext{
${ }^{23}$ Estimating the model including regional dummies does not change this main conclusion. For Italy and Spain regional dummies are significant indicating a higher employment rate in the northern parts (particularly for Italy), while motherhood and other demographic effects are not altered. The estimation results are available from the authors upon request.
} 
observe in Italy a sharp north-south divide with total employment rates in the north being similar to the ones encountered in northern European countries, and very low employment in the south of Italy. In Spain, regional employment differences are not so pronounced as in Italy. However, employment rates are low in all regions with a tendency to increase between 1994 and 2001 in some of these regions. The first two columns for each year in Table 11 show employment rates by region and education for Italy and Spain. We observe that employment rate differences in Italy can be explained by regional differences in the employment rates of low educated women. Employment rates for females with medium and high education do not seem to differ as much across regions. It is the very low employment rates of less educated females especially in the south of Italy, a large group of the population, that account mostly for the employment differences observed. Therefore, the segmentation along education levels seems to have a regional dimension which could not be explained by the supply side factors. This motivates us to consider other explanations to explain such differences.

The ECHP panel allows create indicators of wage trends by regions. ${ }^{24}$ Also we can track features of the wage structure such as the fraction of females working part-time or the fraction of workers in the public sector. These trends can then be used to estimate a correlation with employment rate changes. We do this using the entire "unbalanced" ECHP panel, not restricting to married females with husbands continuously employed. ${ }^{25}$ We perform regressions of female employment rate at the regional level controlling for region and time fixed effects, in Italy, Spain and a third country, Germany, which has also some variation in employment rates at the regional level. Hence, we use the within regional variation to identify correlations. ${ }^{26}$

The first specification we consider only includes regional and year fixed effects. Column 1 of Table 12 gives results of that regression. As expected there is a sharp time trend in employment in Spain while the trend is smaller in Italy. However, there is little trend in employment rates in Germany.

\footnotetext{
${ }^{24}$ Appendix A3 gives more detail on the construction of the regional panel and the variables used in the regressions.

${ }^{25}$ We could also include regional trends into our dynamic models estimated on the balanced panel. Results are quantitatively similar.

${ }^{26}$ We could not get data on childcare institutions and how they vary at the regional level in Spain and Italy. Although some differences may exist, as reported in Del Boca et al. (2002), it is unlikely that these differences evolved differentially over time.
} 
Column 2 adds the mean regional hourly wages in that regression. Goldin (1990) estimates that over the second part of the $20^{\text {th }}$ century, U.S. female employment rose dramatically mostly due to the availability of new jobs. Smith and Ward (1985) estimate increases in the real wage explains $60 \%$ of the rise in female employment in the U.S. over the period 1950-1980. For both in Italy and Spain, changes in wages across regions are indeed found to be positively related to changes in the employment rate. In fact, including the real wage completely eliminates the time trend in employment rates. However, the association is statistically significant only for Spain.

In both Italy and Spain, other trends may also correlate with wage and employment trends. For example, although wages have increased in Spain, it is likely to be heterogeneous across education groups. Although a group's employment may increase with the national wage, it is possible that "externality" effects are also important. One such effect shown to be important in the case of Spain is the "ladder" effect (Collard et al., 2003). High educated females occupy a disproportionately high share of jobs that require less qualification. Hence, as wage increases for that group in high skill jobs, it may improve employment prospects for low skilled workers. Another possibility of heterogeneous effects based on the level of education is statistical discrimination against low educated females exerted by employers, which translates in a higher gender wage gap at the bottom of the wage distribution for low educated and smaller gender wage gap for high educated (de la Rica et. al., 2005). ${ }^{27}$ It may also be that wages increased more rapidly in the low skilled sector because of higher demand in service jobs.

Trends in part-time work may also be important. In Italy, although part-time work is rare, some regions have done better than others to attract female workers into part-time jobs. Hence we include the wage gap between high vs. low educated females (in \%) as well as the $\%$ of females working part-time in year-region. ${ }^{28}$ Since working conditions of

\footnotetext{
${ }^{27}$ The fact that discrimination is higher at the bottom of the distribution is motivated by the larger gap for low educated compared to high educated workers. Reasons behind such discrimination may include higher likelihood of childbearing for low educated and inflexibility of low-skilled jobs compared to jobs for high skilled workers to accommodate childbearing.

${ }^{28}$ In general, the fraction of workers working part-time is not totally demand-driven as it could also reflect variation in the number of kids across regions since women who have kids are more likely to work parttime. Although plausible in Northern Europe, Pissarides et al. (2003) show that the fraction working parttime is more likely to reflect demand constraints in Southern Europe. Females working part-time tend to express lower job satisfaction and in the aggregate part-time work does not appear to correlate with "family considerations" in the South while it does in the North.
} 
female workers in the South might be different between those that work in the public instead of the private sector, we also include the share of females workers employed in the public sector as well as the wage gap between public and private workers.

Column 3 reveals some interesting results. While the mean wage looses some of its statistical significance in Spain, it becomes statistically significant at the $10 \%$ level in Italy. In Spain, it is the wage gap between low and high educated workers that seems positively correlated with the evolution of employment level. The time trend in Spain is again statistically significant but of much smaller magnitude, meaning that the time variation of demand factors has potentially contributed to about half of the increase over time. In Italy, regions that have seen an increase in the percentage of females in part-time work have also seen increases in employment rates. ${ }^{29}$ Furthermore, a widening of the wage gap between public and private workers seemed to be positively correlated with changes in employment rates.

Another factor that might be important for explaining the segmentation of the labor market at the regional level in Italy is social norms and attitudes regarding the role of women. If such social norms exist, they should differ across Italian regions to account for the low female employment in the south of Italy, particularly among the low educated. Table 13 shows data from the World Values Survey (WVS) for 1999 on the right of women to a job, relative to men, by region (North, Center, South) and by education (low vs. middle/high). ${ }^{30}$ The first panel refers to the whole sample. For more educated individuals, the fraction which agrees that men have more right to a job when jobs are scarce is less than $20 \%$ and does not vary across regions. For less educated, we observe a larger fraction who agrees and some variation across regions (34\% for the North vs. $51 \%$ for the South). The data by gender in the next two panels of Table 13 show that the same regional pattern by education holds for both male and female.

These results give confidence that demand factors are likely to play a large role in the recent increase of female employment in Spain and to a lesser extent in Italy, for which social norms seem also to matter. Of course, social norms are not exogenous, i.e.

\footnotetext{
${ }^{29}$ This is in line with Galdeano and Ichino (2005) who find that flexible working arrangements available in part-time employment allows to reconcile motherhood and work.

${ }^{30}$ See Appendx A.4 for a description of the sample and the variables used. The exact question asked is "When jobs are scarce men should have more right to a job than women?"
} 
labor market conditions and preferences shape norms But there is some evidence that more egalitarian norms are perhaps slower to develop in some strata of the population (e.g. the low educated). Since both countries' employment is lagging considerably behind northern countries and the U.S., one could argue that they are undergoing the same demand and societal transformation that other countries have gone through in recent decades.

\section{Conclusion}

This paper studied the stark differences in female employment across 7 European countries using panel data from the ECHP. We found that the education gradient in employment is considerable and steepest in countries with low employment such as Spain and Italy. The large bulk of the North-South employment difference is among low educated married women. Regional analysis shows that in the South, female employment did respond to increases in real wages and other demand factors and that, in the case of Spain, such increase explains much of the push in female employment during the period 1994-2001. Hence, the strong segmentation of the labor market across skill groups and poor employment prospects (in terms of wages) are likely to explain a large share of the differences in employment across countries. In Italy, according to the World Value Survey, the large regional variation may also be explained by social norms. Both females and males in the South tend to agree more often that when jobs are scarce, men should be given precedence over women. This is particularly true among low educated individuals, where simultaneously the largest employment differences are observed.

Furthermore, we find that the positive correlation between persistence and employment levels is likely the result of that same heterogeneity or segmentation of the labor market. The estimation of dynamic models studying state-dependence and heterogeneity at the individual level do not yield a state-dependence pattern that is in line with employment levels, indeed Spain and Italy have lower state-dependence effects than countries such as the U.K. and France. Garibaldi and Wasmer (2004) show that the effect of frictions, what state-dependence may proxy for, on employment is indeterminate and depends on the distribution of wage offers and reservation wages. 
On the other hand, the estimated effects of motherhood on employment were largest in countries that have generous child benefits, while these countries have also high employment rates. Our results suggest that motherhood penalties cannot explain the large North-South differences in employment rates. Effects are lowest in Italy. Time use data shows that Italian women who have children spend much less time in childcare than in other countries. This may indicate that women who decide to have children in Italy, the country with the lowest fertility rate in Europe, have other resources, either familial or financial to minimize the time-crunch of motherhood.. However, irrespective of the number of children, Italian women spend considerable time in household production, more so than in other countries. On the other hand, the dynamic effect of motherhood helps however explain differences in the North, particularly for the Netherlands, where females stay out of regular employment (more than $15 \mathrm{hrs}$ a week) for many years after giving birth. This is in sharp contrast to the U.K., Denmark or France, where higher employment and shorter exits from the labor force are observed.

The cost for such long absence from regular employment may be large in terms of forfeited experience in the labor market, and it would in principle be possible to calculate such effects from the ECHP panel. It remains an open question if there is a link between the length of exits from the labor force due to motherhood and the gender wage gap across countries. This link is highly important because it serves as a basis for models that explain the gender wage gap through statistical discrimination as well as intertemporal labor supply models that study the fertility and labor supply decisions of females with different returns to experience. 


\section{References}

Ahn, N. and P. Mira (2002): "A Note on the Relationship between Fertility and Female Employment Rates in Developed Countries", Journal of Population Economics, $14: 3$, pp. 505-522.

Azmat, G., Guell, M. and Manning, A. (2004): "Gender Gaps in Unemployment Rates in OECD Countries", CEPR Working Paper, No 0607.

Carro, J. (2003): "Estimating Dynamic Panel Data Discrete Choice Models with Fixed Effects", CEMFI discussion paper 304.

Chamberlain, G. (1984): "Heterogeneity, Omitted Variables and Duration Dependence", in Longitudinal Analysis of Labor Market Data, eds, Heckman, J.J. and Singer, B., Econometric Society Monograph chapter 1, pp. 3-38.

Chay, K.Y. and Hyslop, D.R. (2001): "Identification and Estimation of Dynamic Binary Response Panel Data Models: Empirical Evidence using Alternative Approaches", manuscript

Collard, F., Fonseca, R. and R. Munoz (2003): "Spanish Unemployment Persistence and the Ladder Effect", CSEF working paper 106. http://www.dise.unisa.it/WP/wp106.pdf

Del Boca, D. (2002): “The Effect of Child Care and Part Time Opportunities on Participation and Fertility Decisions in Italy", Journal of Population Economics, 15:3, pp. 549-573.

Freeman, R. and R. Schettkat (2002): "Marketization of Production and the U.S.-Europe Employment Gap", NBER Working Paper 8797.

Galdeano, A. and Ichino, A. (2005): "Reconciling Motherhood and Work: Evidence from Time Use Data in Three Countries", in Hamermesh, Dan, and Gerard Pfann (Eds.), The Economics of Time Use, Amsterdam, Elsevier.

Garibaldi, P. and E. Wasmer (2004): "Raising Female Employment: Reflexions and Policy Tools", Journal of the European Economic Association, 2, 2-3, pp. 320-330. Goldin C. (1990) Understanding the Gender Gap, Oxford University Press, 1990.

Greenwood J., A. Seshadri and M. Yorukoglu (2002), "Engines of Liberation," Economie D'Avant Garde Research Reports, University of Rochester

Gustafsson, S. (1992): "Separate Taxation and Married Women's Labor Supply. A Comparison of West Germany and Sweden", Journal of Population Economics 5, pp.61-85.

Heckman, J.J. (1993): "What Has Been Learned About Labor Supply in the Past Twenty Years", AER Papers and Proceedings of the 105th AEA Annual Meeting, pp. 116121.

Heckman, J.J. and B. Singer (1984): "A Method for Minimizing the Impact of Distributional Assumptions in Econometric Models for Duration Data", Econometrica 52, pp. 271-320.

Heckman, J.J. (1981): "The Incidental Parameters Problem and the Problem of Initial Condition in Estimating a Discrete-Time Data Stochastic Process", in Structural Analysis of Discrete Data with Econometric Applications, C.F. Manski and D. McFadden eds. , MIT Press, Cambridge, pp. 179-195. 
Heckman, J.J. and Willis, R. (1977): "A Beta-Logistic Model for the Analysis of Sequential Labor Force Participation by Married Women", Journal of Political Economy, 85(1). pp. 27-58.

Honore, B.E. and Kyriazidou, E. (2000): "Panel Data Discrete Choice Models with Lagged Dependent Variables", Econometrica, 68, pp. 839-874.

Hyslop, D.R. (1999): "State Dependence, Serial Correlation and Heterogeneity in Intertemporal labour Supply Participation of Married Women", Econometrica 67:6, pp.1255-1294.

Layard, R., Nickell, S. and Jackman, R. (1991): "Unemployment: Macroeconomic Performance and the Labour Market", Oxford University Press.

MOCHO (2004): "The Rationale of Motherhood Choices: Influences of Employment Conditions and of Public Policies", Final report.

Mundlack, Y.(1978), "On the pooling of time series and cross-sectional data", Econometrica, 46, 69-86.

OECD (2003): "Taxing Wages 2001-2002", Paris, p. 40.

Pissarides, C., Garibaldi, P., Olivetti, Petrongolo, B. and E. Wasmer (2003): "Women in the Labour Force: How Well is Europe Doing?", paper presented at the 5th European Conference of the Fondazione Debenedetti, www.frdb.org.

Sleebos (2003): "Low Fertility Rates in OECD Countries", OECD Labour Market and Social Policy Occasional Papers, 15.

Smith J.P. and Ward M. P. (1985) "Time-Series Growth in the Female Labor Force."

Journal of Labor Economics, 3: 59-90.

Wooldridge, J.M.. (2005), "Simple Solutions to the Initial Conditions Problem in Dynamic, Nonlinear Panel Data Models with Unobserved Heterogeneity", Journal of Applied Econometrics. 


\section{Appendix A: Construction of Analytic Files}

\section{A.1 European Community Household Balanced Panel}

We use the full panel of the ECHP (1994-2001) selecting females who are aged 20-45 years old at the first year and who are married or cohabiting, which we refer as married. For the main part of the analysis we focus on a balanced panel of married females with husbands continuously employed during the eight years of the panel. Table A1.1 shows the sample size that emerges out of this selection starting from the total sample of married females.

\begin{tabular}{lccccccc}
\hline \hline Table A1.1. Sample Selection & & & & & & & \\
& & & & & & & \\
& Netherlands & Denmark & France & Italy & Spain & Germany & U.K. \\
Total Sample & 37371 & 21721 & 46695 & 59059 & 51262 & 47115 & 32922 \\
Females aged 20-45 & 14721 & 7917 & 16682 & 20278 & 17924 & 18673 & 11758 \\
Balanced Sample & 5768 & 3920 & 8648 & 10320 & 8296 & 10168 & 6584 \\
$\quad$ \% of Obs. Dropped & 60.82 & 50.49 & 48.16 & 49.11 & 53.72 & 45.55 & 44.00 \\
Husbands Employed & 4928 & 3464 & 6576 & 8240 & 5560 & 7256 & 4744 \\
$\quad$ \% of Obs. Dropped & 14.56 & 11.63 & 23.96 & 20.16 & 32.98 & 28.64 & 27.95 \\
Final Sample & 4696 & 3384 & 6264 & 8024 & 5360 & 6800 & 4336 \\
\hline \hline
\end{tabular}

Table A1.2 compares the mean characteristics between the balanced and unbalanced sample, and between the sample with husbands continuously employed or not. We report the following characteristics: employment, age, high education, health status, and number of kids. Comparing the balanced with the unbalanced sample we do not observe overall big differences. Employment rates differences are of the order of a third or less of 1 percentage point, except for Denmark which is slightly higher. This indicates that attrition and non-response does not seem to be associated with some of the important variables used in the analysis, including employment.

The comparison between the samples with husbands continuously employed during the eight waves and the one in which husbands face employment transitions reveals some differences. In Denmark, France, and the U.K., females with husbands working during all years have higher employment rates. They are also more educated, they report worse health, and they have fewer kids (except in the UK). In Germany, there seems to be no difference along all these dimensions. 


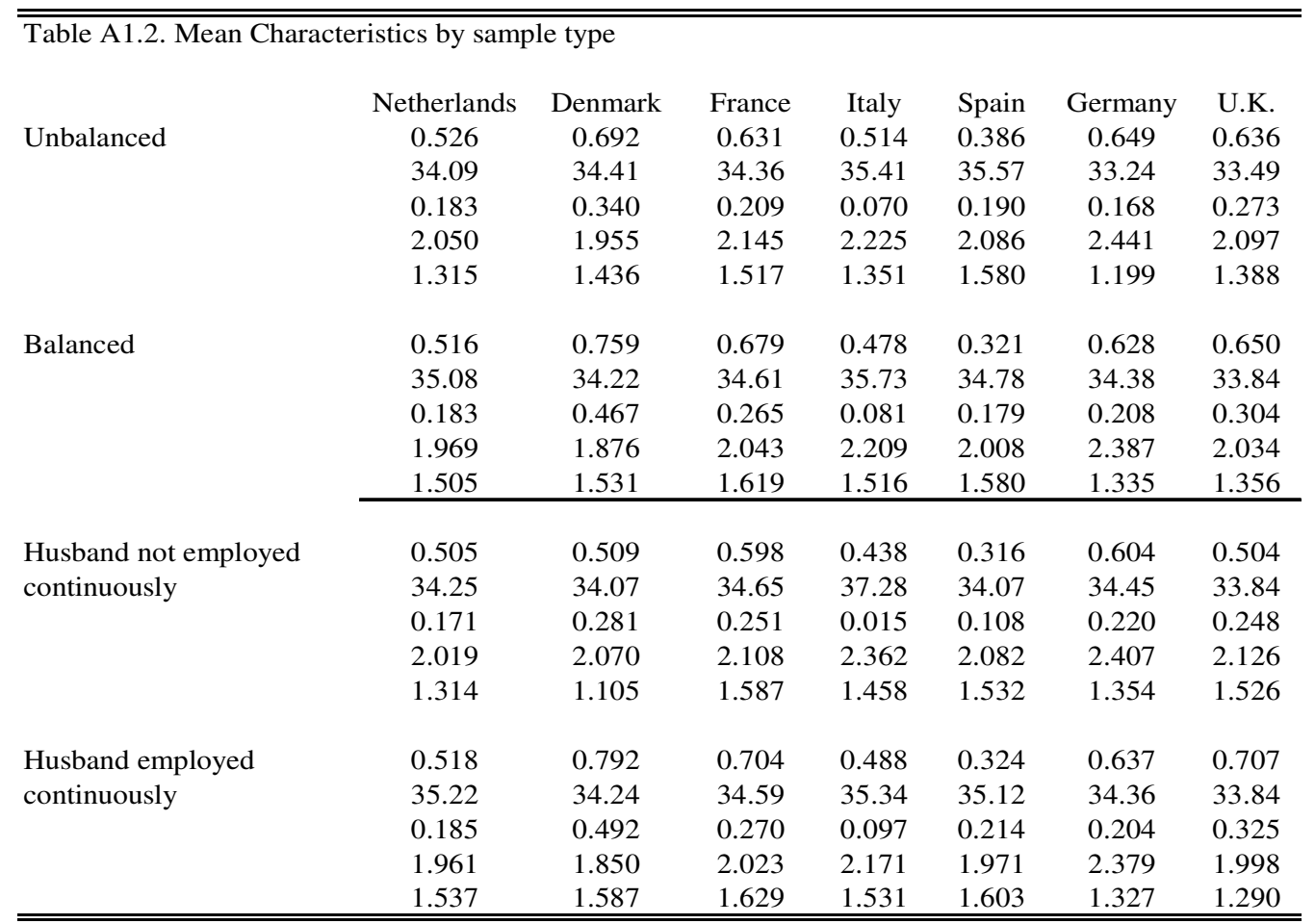

Note: Mean characteristics for employment, age, high education, health status (1=very good, $5=$ bad) and number of kids

\section{A.2 Multinational Time Use Study}

We used release World5.5 of the Multinational Time Use Study available at (http://www.iser.essex.ac.uk). We use micro-data from 1995 in the U.K. and the Netherlands, 1998 in France, 1992 in Germany and 1989 in Italy. The MTUS contains harmonized aggregated time spent per day in 41 categories as well as a limited set of characteristics that can be exploited. The Dutch survey reports daily averages over a week while for the other countries, data is reported for a particular day. We selected married or cohabiting males or females aged 20 to 45 who are not in school. We also selected on diaries reported during weekdays or week average. We used sampling weights in Table 3.

After deleting observations with important missing information, we are left with the following number of observations.

\begin{tabular}{lrrr}
\hline \hline survey & male & female & Total \\
France & 1,204 & 1,400 & 2,604 \\
Netherlands & 436 & 558 & 994 \\
UK & 142 & 169 & 311 \\
Italy & 1,551 & 1,815 & 3,366 \\
Germany & 1,599 & 1,839 & 3,438 \\
\hline Total & 4,932 & 5,781 & 10,713 \\
\hline
\end{tabular}




\section{A.3 Regional Panel from ECHP}

We construct the regional panel for Italy, Spain, and Germany using all females aged 1864 for each country, that is we do not make restrictions on the family structure and we consider the unbalanced panel. The wages at the regional level are constructed as follows: using the calendar of activities we obtain the number of months each female has spent in employment, unemployment and inactivity during the previous year. We then construct the monthly wage by dividing the total earnings during the previous year by the number of months spent in employment, which we express in 1994 prices using the CPI. We then obtain the mean wage by region and year for each country by collapsing the female wage information at the regional level. We follow the same procedure to construct the mean earnings at the regional level by education level and by public sector employment. We use these variables to construct the high vs. low education earnings ratio, and the public vs. private sector. The time series at the regional level were smoothed using a moving average when there were few observations in cells. Finally, using the individual information on part-time and public employment we construct the share of females at the regional level in part-time and in public employment by year.

\section{A.4 World Value Survey for Italy}

We use information from the World Values Survey (WVS) for Italy in 1999 on the extent to which individuals agree with the following statement: "When jobs are scarce men should have more right to a job than women". Possible answers include "Agree", "Disagree", "Neither". The total sample is 2000 individuals of which 1041 are females. We distinguish between North, Centre, and South using the regional information which is grouped using the NUTS regional codes. The low education group includes those who completed elementary school, or lower, and those who did not complete secondary school. The middle education group contains those who completed secondary education (either technical or university preparation), and the high education refers to those who have some university educaton without degree and the university graduates. 


\section{Figures}

Figure 1 Simulation of the Effect of a First Birth for a Mother Aged 25-30 with Average Characteristics on Employment (working more than 15 hrs per week)

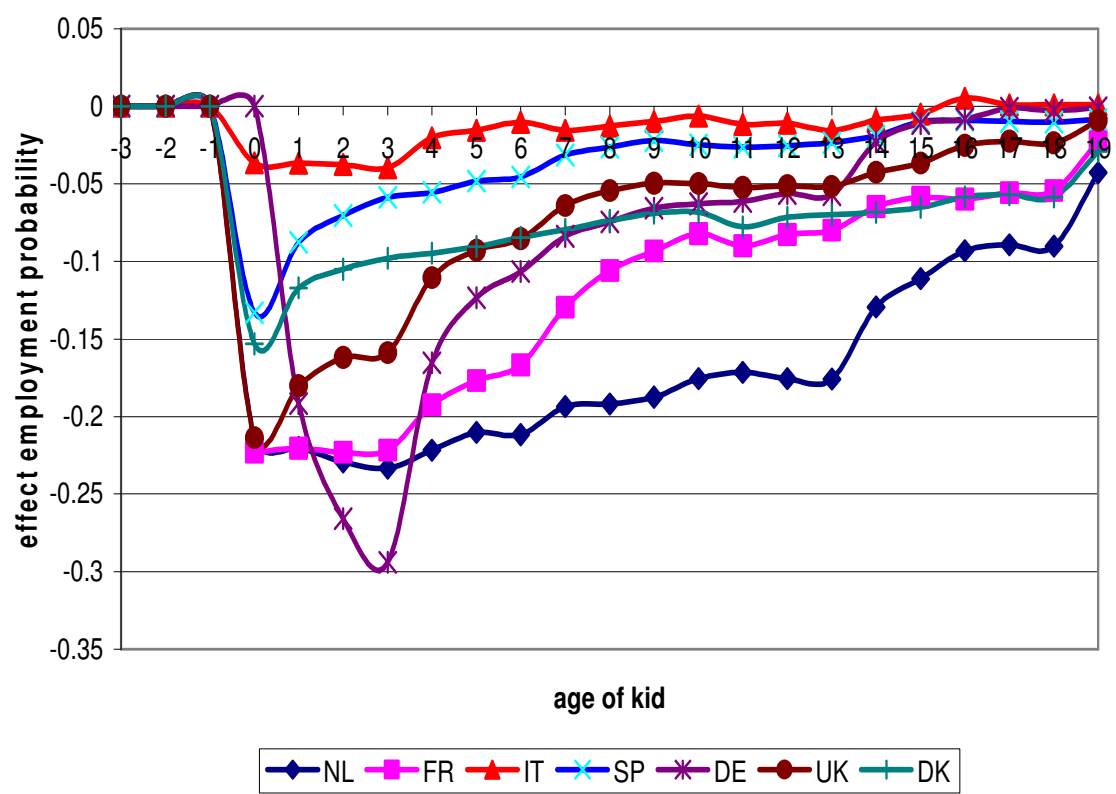

Notes: Based on simulated probabilities for a married female with average employment probability. 5000 replications used and employment rates weighted over the various unobserved heterogeneity types. 
Figure 2 Simulation of the Effect of a First Birth for a Mother Aged 25-30 with Average Characteristics on Employment Rate (working more than $1 \mathrm{hr}$ per week)

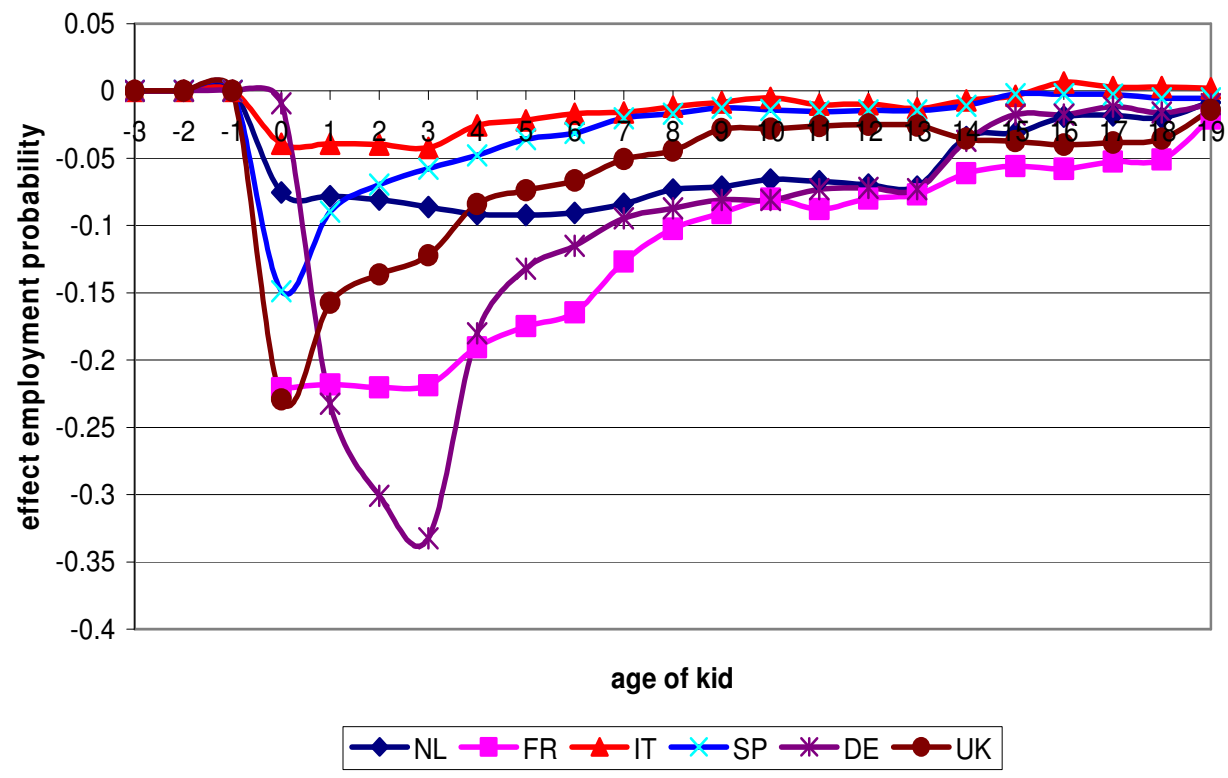

Notes: Based on simulated probabilities for a married female with average employment probability. 5000 replications used and employment rates weighted over the various unobserved heterogeneity types. 


\section{Tables}

Table 1 Evolution of Employment Rates in the 1994-2001 Panel

\begin{tabular}{lccrrrrrrrr}
\hline \hline Country & (1994 Estat) & (2001 Estat) & 1994 & 1995 & 1996 & 1997 & 1998 & 1999 & 2000 & 2001 \\
\hline Netherlands & 0.603 & 0.725 & 0.509 & 0.509 & 0.513 & 0.503 & 0.552 & 0.552 & 0.579 & 0.600 \\
France & 0.670 & 0.711 & 0.706 & 0.709 & 0.724 & 0.687 & 0.686 & 0.690 & 0.701 & 0.718 \\
Italy & 0.463 & 0.528 & 0.490 & 0.493 & 0.489 & 0.491 & 0.488 & 0.520 & 0.517 & 0.512 \\
Spain & 0.389 & 0.529 & 0.330 & 0.336 & 0.328 & 0.352 & 0.366 & 0.378 & 0.400 & 0.427 \\
Germany & 0.658 & 0.716 & 0.638 & 0.641 & 0.633 & 0.626 & 0.627 & 0.648 & 0.655 & 0.675 \\
United Kingdom & 0.692 & 0.735 & 0.694 & 0.708 & 0.723 & 0.710 & 0.718 & 0.720 & 0.742 & 0.725 \\
Denmark & 0.751 & 0.806 & 0.792 & 0.752 & 0.754 & 0.778 & 0.783 & 0.780 & 0.790 & 0.775 \\
\hline \hline
\end{tabular}

Source: Eurostat based on females aged 25-54 years old. ECHP (1994-2001) based on a balanced sample of married females aged 2545 in 1994

Table 2 Employment Rates by Education and the Presence of Kids aged 0-5

\begin{tabular}{lccrrrr}
\hline \hline & \multicolumn{2}{c}{ Low Education } & \multicolumn{2}{c}{ Medium Education } & \multicolumn{2}{c}{ High Education } \\
Country & no kids & with kids & no kids & with kids & no kids & with kids \\
\cline { 2 - 7 } Netherlands & 0.340 & 0.389 & 0.522 & 0.458 & 0.756 & 0.735 \\
France & 0.597 & 0.384 & 0.751 & 0.599 & 0.906 & 0.770 \\
Italy & 0.352 & 0.281 & 0.610 & 0.578 & 0.783 & 0.756 \\
Spain & 0.287 & 0.165 & 0.374 & 0.401 & 0.615 & 0.665 \\
Germany & 0.601 & 0.418 & 0.658 & 0.441 & 0.886 & 0.554 \\
United Kingdom & 0.762 & 0.538 & 0.785 & 0.487 & 0.864 & 0.627 \\
Denmark & 0.638 & 0.458 & 0.699 & 0.792 & 0.906 & 0.860 \\
\hline \hline
\end{tabular}

Notes: employment rates by level of education and the presence of kids $0-5$ years old. Pooled over all waves. 
Table 3 Time Use on Market, Home Production and Childcare across Countries

\begin{tabular}{|c|c|c|c|c|c|}
\hline \multirow{2}{*}{ country } & \multirow{2}{*}{$\begin{array}{l}\text { avg. hours } \\
\text { per day }\end{array}$} & \multicolumn{2}{|c|}{ not working } & \multicolumn{2}{|c|}{ working } \\
\hline & & no kids & kids & no kids & kids \\
\hline \multirow[t]{3}{*}{ France } & market & & & 7.46 & 5.87 \\
\hline & home & 3.76 & 4.51 & 1.97 & 2.46 \\
\hline & childcare & & 1.86 & & 1.20 \\
\hline \multirow[t]{3}{*}{ Netherlands } & market & & & 4.76 & 3.02 \\
\hline & home & 2.13 & 3.59 & 1.67 & 2.53 \\
\hline & childcare & & 1.62 & & 1.31 \\
\hline \multirow[t]{3}{*}{ UK } & market & & & 7.25 & 4.57 \\
\hline & home & 3.50 & 3.49 & 1.45 & 2.67 \\
\hline & childcare & & 3.51 & & 2.26 \\
\hline \multirow[t]{3}{*}{ Italy } & market & & & 6.10 & 5.12 \\
\hline & home & 6.50 & 6.70 & 3.35 & 4.10 \\
\hline & childcare & & 1.56 & & 1.09 \\
\hline \multirow[t]{3}{*}{ Germany } & market & & & 7.48 & 4.49 \\
\hline & home & 3.75 & 4.02 & 1.61 & 2.56 \\
\hline & childcare & & 3.29 & & 2.20 \\
\hline
\end{tabular}

Notes: Own calculations from MTUS. Employment question refers to the previous week. Kids refer to the presence of kids under the age of 5. Women aged 25-45. 


\section{Table 4 Child Benefits, Maternity Leave and Child Care across Countries}

\begin{tabular}{|c|c|c|c|}
\hline Birth Grants & Application & Amount & Duration \\
\hline Denmark & Birth of more than 1 child & 64 per month/child & Up to 7 years old \\
\hline France & From 1st Child & 148 per month/child & Up to 3 years old \\
\hline Germany & From 1st Child & 304 per month/child & Up to 2 years old \\
\hline Italy & None & & \\
\hline Netherlands & None & & \\
\hline Spain & None & & \\
\hline United Kingdom & $\begin{array}{l}\text { For each child if in receipt } \\
\text { of income-related benefits }\end{array}$ & $\begin{array}{l}\text { Payment of } 124 \text { for } \\
\text { each baby expected }\end{array}$ & \\
\hline \multicolumn{4}{|c|}{ Source: MISSOC (1998), Eurostat. Amounts reported in ECU. } \\
\hline Family Allowances & $\begin{array}{c}\text { Application } \\
\end{array}$ & Amount & Duration \\
\hline Denmark & From 1st Child & $\begin{array}{l}\text { 122-259 per month for each } \\
\text { child depending on age }\end{array}$ & 18 years old \\
\hline France & From 2nd Child & $\begin{array}{l}103-632 \text { per month depending } \\
\text { on number of children }\end{array}$ & 19 years old \\
\hline Germany & From 1st Child & $\begin{array}{l}111-177 \text { per month depending } \\
\text { on number of children }\end{array}$ & 18 years old \\
\hline Italy & From 1st Child & $\begin{array}{l}77-130 \text { per month depending } \\
\text { on family income }\end{array}$ & 18 years old \\
\hline Netherlands & From 1st Child & $\begin{array}{l}47-67 \text { per month for each } \\
\text { child depending on age }\end{array}$ & 17 years old \\
\hline Spain & From 1st Child & 18-36 per month for each child & 18 years old \\
\hline United Kingdom & From 1st Child & $\begin{array}{l}72 \text { per month for eldest child } \\
58 \text { for each other child }\end{array}$ & 16 years old \\
\hline \multicolumn{4}{|c|}{ Source: MISSOC, (1998) Eurostat. Amounts reported in ECU. } \\
\hline $\begin{array}{l}\text { Maternity/ child care } \\
\text { leave for } 1999 / 2000\end{array}$ & $\begin{array}{c}\text { Duration of maternity } \\
\text { leave (weeks) }\end{array}$ & $\begin{array}{c}\text { Maternity benefits } \\
\text { (\% if average wages) }\end{array}$ & $\begin{array}{c}\text { Total duration of } \\
\text { maternity/child-care } \\
\text { leave (weeks) }\end{array}$ \\
\hline Denmark & 30 & 100 & 82 \\
\hline France & 16 & 100 & 162 \\
\hline Germany & 14 & 100 & 162 \\
\hline Italy & 21.5 & 80 & 64.5 \\
\hline Netherlands & 16 & 100 & 68 \\
\hline Spain & 16 & 100 & 164 \\
\hline United Kingdom & 18 & 44 & 44 \\
\hline \multicolumn{4}{|c|}{ Source: CESifo - Dice based on OECD Employment Outlook 2001, p. 144.} \\
\hline \multirow[t]{2}{*}{ Child care } & \multicolumn{2}{|c|}{ Coverage (Opening hours) } & \\
\hline & $0-3$ Yrs old & $3-6$ Yrs old & \\
\hline Denmark & $58 \%(11)$ & $90 \%(11)$ & \\
\hline France & $39 \%(10.2)$ & $87 \%(8)$ & \\
\hline Germany & $9 \%(10)$ & $73 \%(6.7)$ & \\
\hline Italy & $6 \%(10)$ & $95 \%(8)$ & \\
\hline Netherlands & $2.3 \%(10.5)$ & $66 \%(5.5)$ & \\
\hline Spain & $5 \%(7)$ & $77 \%(5)$ & \\
\hline United Kingdom & $2 \%(8)$ & $60 \%(5.2)$ & \\
\hline
\end{tabular}

Source: MOCHO (2004). Amounts reported in ECU 
Table 5 Persistence in the ECHP Balanced Panel (1994-2001)

\begin{tabular}{|c|c|c|c|c|c|c|c|c|}
\hline \multirow[b]{2}{*}{ Country } & \multirow{2}{*}{\multicolumn{2}{|c|}{$\begin{array}{l}\text { employment mobility } \\
\text { rate }(\mathrm{t}) \text { index }\end{array}$}} & \multicolumn{2}{|c|}{$\begin{array}{l}\text { \% working at } \mathrm{t} \text { as fraction } \\
\text { of work status (t-1) }\end{array}$} & \multicolumn{4}{|c|}{ \% for \# of Transitions 1994-2001 } \\
\hline & & & not working & working & 0 & 1 & 2 & 3 \\
\hline Netherlands & 0.544 & 0.180 & 0.108 & 0.929 & 62.7 & 22.8 & 7.7 & 6.8 \\
\hline France & 0.702 & 0.188 & 0.133 & 0.945 & 68.8 & 14.4 & 12.0 & 4.7 \\
\hline Italy & 0.501 & 0.125 & 0.066 & 0.940 & 76.3 & 10.3 & 8.4 & 5.1 \\
\hline Spain & 0.370 & 0.172 & 0.075 & 0.903 & 69.3 & 15.1 & 7.8 & 7.9 \\
\hline Germany & 0.644 & 0.259 & 0.171 & 0.912 & 57.5 & 17.4 & 15.2 & 9.9 \\
\hline United Kingdom & 0.721 & 0.278 & 0.204 & 0.926 & 57.2 & 20.7 & 12.9 & 9.2 \\
\hline Denmark & 0.773 & 0.150 & 0.114 & 0.964 & 78.7 & 10.4 & 6.9 & 4.0 \\
\hline
\end{tabular}

Notes: Calculations from ECHP balanced panel 1994-2001. Pooled transitions and mobility index defined as in Shorrocks (1978). 


\section{Table 6 Dynamic Employment Equation Estimates using Wooldridge Initial Condition Solution}

\begin{tabular}{|c|c|c|c|c|c|c|c|}
\hline & $\begin{array}{l}\text { Netherlands } \\
\text { Avg. PE }\end{array}$ & $\begin{array}{l}\text { France } \\
\text { Avg. PE }\end{array}$ & $\begin{array}{l}\text { Italy } \\
\text { Avg. PE }\end{array}$ & $\begin{array}{l}\text { Spain } \\
\text { Avg. PE }\end{array}$ & $\begin{array}{l}\text { Germany } \\
\text { Avg. PE }\end{array}$ & $\begin{array}{l}\text { UK } \\
\text { Avg. PE }\end{array}$ & $\begin{array}{l}\text { Denmark } \\
\text { Avg. PE }\end{array}$ \\
\hline$<30$ & $-0.079^{* *}$ & -0.030 & -0.003 & -0.046 ** & -0.002 & 0.007 & $-0.045^{\star *}$ \\
\hline $35-40$ & 0.045 ** & 0.004 & 0.024 * & 0.030 ** & 0.016 & -0.006 & 0.002 \\
\hline $40+$ & 0.109 ** & -0.008 & 0.052 ** & $0.097^{* *}$ & 0.019 & 0.009 & 0.019 \\
\hline mided & $0.055^{* *}$ & 0.022 & $0.061^{* *}$ & 0.079 ** & 0.016 & -0.013 & 0.010 \\
\hline highed & 0.116 ** & 0.079 ** & $0.182^{* *}$ & 0.140 ** & $0.107^{* *}$ & 0.023 & 0.069 ** \\
\hline health good & -0.018 & -0.010 & 0.011 & -0.003 & 0.008 & 0.007 & -0.009 \\
\hline health bad & $-0.066^{* *}$ & -0.024 * & 0.012 & 0.024 * & $-8.5 E-05$ & -0.022 & -0.026 * \\
\hline trans. Income husb & -0.017 & -0.003 & -0.090 * & 0.065 & $-0.184^{* *}$ & -0.034 & -0.004 \\
\hline 1st birth & $-0.180 * *$ & -0.226 ** & -0.043 * & -0.116 ** & 0.038 & $-0.231^{* *}$ & -0.142 ** \\
\hline 2nd + birth & $-0.117^{* *}$ & $-0.246 * *$ & -0.018 & -0.046 & -0.056 * & $-0.166^{* *}$ & $-0.074^{* *}$ \\
\hline \#kids 1-3 & $-0.108^{* *}$ & $-0.094 * *$ & -0.027 * & -0.035 * & $-0.183^{* *}$ & $-0.099 * *$ & $-0.029 * *$ \\
\hline \#kids 4-6 & $-0.095 * *$ & $-0.068 * *$ & -0.001 & -0.029 * & $-0.064 * *$ & $-0.053 * *$ & $-0.026^{* *}$ \\
\hline \#kids 7-12 & -0.082 ** & -0.040 ** & -0.009 & -0.015 & $-0.041 * *$ & $-0.035 * *$ & -0.023 ** \\
\hline \# kids $13-18$ & $-0.040 * *$ & $-0.025 * *$ & $-5.2 E-05$ & -0.010 & -0.002 & -0.019 & -0.019 \\
\hline perm. Income husb & $-0.121 *$ & $-0.065^{* *}$ & -0.135 & -0.117 & $-0.334^{* *}$ & $-0.143^{* *}$ & -0.021 \\
\hline Cohort Year/1000 & 0.111 ** & 0.022 & $0.048^{* *}$ & $0.107^{* *}$ & $0.047^{* *}$ & $0.063^{* *}$ & 0.009 \\
\hline $\begin{array}{l}\text { LR Test Kids (DF=8) } \\
\text { State-dependence }\end{array}$ & $32.73^{* *}$ & $16.90^{* *}$ & 12.92 & 9.41 & 13.83 * & $45.85^{* *}$ & 25.54 ** \\
\hline $\begin{array}{l}\text { work }(\mathrm{t}-1) \\
\text { Heterogeneity }\end{array}$ & 0.309 ** & 0.372 ** & $0.234 * *$ & $0.210^{* *}$ & $0.248^{* *}$ & $0.305^{* *}$ & 0.189 ** \\
\hline $\begin{array}{l}\text { Heterogeneity } \\
\text { Point } 2 \text { (Point } 1=0)\end{array}$ & $-1295 * *$ & 1628 ** & $-1983 * *$ & $1756 * *$ & 1005 ** & ค ח ח * * & \\
\hline $\begin{array}{r}\text { Prob } 2 \\
\text { P }\end{array}$ & $0.127 * *$ & $0.185^{* *}$ & 0.233 ** & $\begin{array}{r}-1.756^{* *} \\
0.479^{* *}\end{array}$ & $\begin{array}{r}-1.385^{* *} \\
0.211^{* *}\end{array}$ & $\begin{array}{l}0.902^{\star *} \\
0.329^{* *}\end{array}$ & $\begin{array}{r}-2.155^{\star *} \\
0.340^{* *}\end{array}$ \\
\hline Point 3 (Prob) & 1.539 ** & $-1.319 * *$ & $1.581 * *$ & $-3.654 * *$ & 1.409 ** & $-1.242 * *$ & $2.181^{* *}$ \\
\hline Prob 3 & $0.341^{* *}$ & $0.132^{* *}$ & 0.150 ** & $0.178^{* *}$ & $0.203^{* *}$ & 0.141 ** & $0.343^{* *}$ \\
\hline share unobserved het & 0.653 ** & 0.542 ** & $0.760 * *$ & $0.769 * *$ & 0.569 ** & 0.456 ** & $0.861^{* *}$ \\
\hline t-test initial cond. & $9.67^{* *}$ & $10.27^{* *}$ & 12.74 ** & 9.32 ** & $12.17^{* *}$ & $8.07^{* *}$ & $5.48^{* *}$ \\
\hline 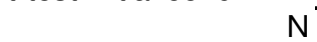 & 587 & 783 & 1003 & 670 & 850 & 542 & 423 \\
\hline LogLikelihood/N & -1.878 & -1.672 & -1.406 & -1.729 & -2.176 & -2.083 & -1.222 \\
\hline
\end{tabular}

Notes: Average partial effects (APE) based on Maximum likelihood estimates implementing the Wooldridge (2005) initial condition solution. APE are calculated using the numerical derivative of the predicted probability for each individual and type and then 
Table 7 Dynamic Employment Equation Estimates using Heckman Initial Condition Solution

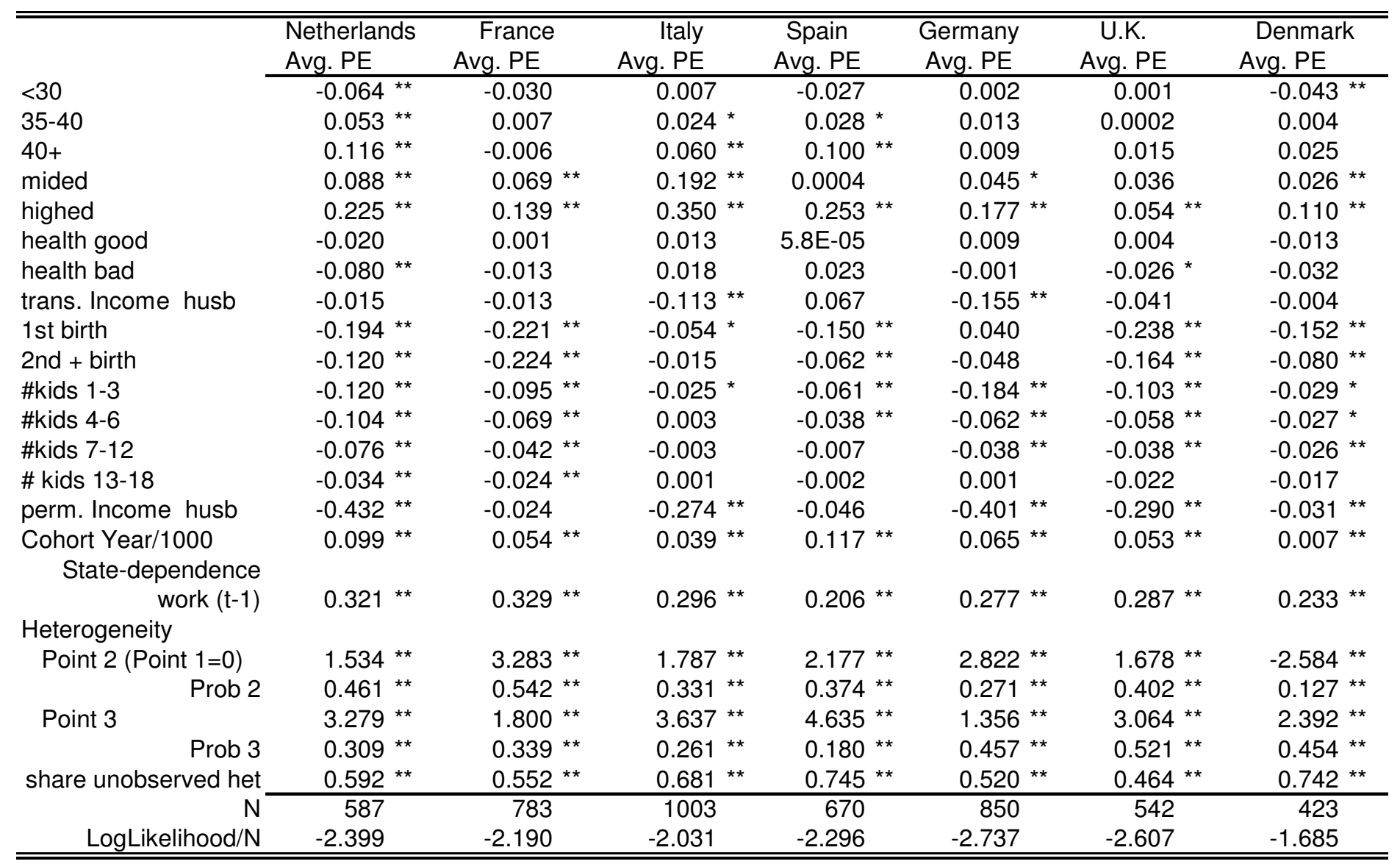

Notes: Average partial effects (APE) based on Maximum likelihood estimates implementing the Heckman (1981) initial condition solution. Initial condition estimates not shown but can be provided upon request. APE are calculated using the numerical derivativ 
Table 8 Definition of Employment by Number of Hours Worked

\begin{tabular}{lrrr}
\hline \hline Country & not working & work 1-15 hrs & work 15+ hrs \\
\cline { 2 - 4 } Netherlands & 32.28 & 13.76 & 53.96 \\
France & 29.69 & 0.05 & 70.26 \\
Italy & 49.41 & 0.6 & 49.99 \\
Spain & 61.47 & 2.07 & 36.46 \\
Germany & 27.46 & 8.25 & 64.29 \\
United Kingdom & 20.85 & 7.4 & 71.75 \\
Denmark & 20.12 & 2.33 & 77.54 \\
Total & 36.25 & 4.55 & 59.2 \\
\hline \hline Notes: females under age 40 & \multicolumn{3}{l}{}
\end{tabular}

Notes: females under age 40

Table 9 Hours worked and Presence of Kids under age of 3

\begin{tabular}{lcccccc}
\hline \hline & \multicolumn{3}{c}{ Education level and presence of kids under age of 3 } \\
\cline { 2 - 6 } Country & \multicolumn{2}{c}{ low } & \multicolumn{5}{c}{ medium } & \multicolumn{3}{c}{ high } \\
Netherlands & 0.353 & 0.357 & 0.249 & 0.263 & 0.106 & 0.074 \\
& 0.647 & 0.643 & 0.751 & 0.737 & 0.894 & 0.926 \\
no kids & kids & no kids & kids & no kids & kids \\
\cline { 2 - 7 } Germany & 0.167 & 0.143 & 0.161 & 0.178 & 0.041 & 0.078 \\
& 0.833 & 0.857 & 0.839 & 0.822 & 0.959 & 0.922 \\
United Kingdom & 0.138 & 0.207 & 0.069 & 0.223 & 0.067 & 0.097 \\
& 0.862 & 0.793 & 0.931 & 0.777 & 0.933 & 0.903 \\
\hline \hline
\end{tabular}

Notes: Fraction of workers working under and over 15 hrs per week(conditional on working), females under age 40 
Table 10 Heterogeneity of Motherhood Effects by Level of Education

\begin{tabular}{|c|c|c|c|c|c|c|c|}
\hline & $\begin{array}{l}\text { Netherlands } \\
\text { APE }\end{array}$ & $\begin{array}{l}\text { France } \\
\text { APE }\end{array}$ & $\begin{array}{l}\text { Italy } \\
\text { APE }\end{array}$ & $\begin{array}{l}\text { Spain } \\
\text { APE }\end{array}$ & $\begin{array}{l}\text { Germany } \\
\text { APE }\end{array}$ & $\begin{array}{l}\text { UK } \\
\text { APE }\end{array}$ & $\begin{array}{l}\text { Denmark } \\
\text { APE }\end{array}$ \\
\hline \multicolumn{8}{|l|}{ birth (pooled 1st,2nd +) } \\
\hline low & -0.134 & $-0.239 * *$ & -0.068 ** & -0.088 ** & -0.108 & $-0.209 * *$ & -0.043 \\
\hline medium & $-0.158 * *$ & -0.262 ** & -0.019 & -0.003 & -0.011 & $-0.227^{* *}$ & $-0.086 *$ \\
\hline $\begin{array}{l}\text { high } \\
\text { stock 0-3 }\end{array}$ & $-0.089 *$ & -0.222 ** & 0.040 & -0.053 & -0.073 & -0.162 ** & $-0.107^{* *}$ \\
\hline low & -0.065 & -0.116 ** & -0.003 & $-0.060 * *$ & -0.132 ** & $-0.078^{* *}$ & -0.029 \\
\hline medium & -0.108 ** & $-0.073 * *$ & $-0.040 * *$ & -0.018 ** & $-0.198 * *$ & -0.080 & -0.026 \\
\hline high & -0.088 ** & -0.112 ** & -0.100 ** & -0.031 & -0.166 ** & -0.108 ** & $-0.025 * *$ \\
\hline \multicolumn{8}{|l|}{ stock 4-6 } \\
\hline low & $-0.120 * *$ & -0.082 ** & 0.020 & $-0.040 *$ & $-0.102 * *$ & -0.034 & -0.011 \\
\hline medium & $-0.082 * *$ & $-0.067 * *$ & $-0.021 *$ & -0.039 & -0.056 ** & -0.041 & -0.017 \\
\hline high & $-0.114 * *$ & -0.060 ** & -0.007 & -0.006 & $-0.091^{* *}$ & $-0.058 * *$ & $-0.036 * *$ \\
\hline \multicolumn{8}{|l|}{ stock 7-12 } \\
\hline low & -0.086 ** & $-0.044 * *$ & -0.004 & -0.010 & -0.015 & -0.023 & -0.010 \\
\hline medium & $-0.077^{* *}$ & -0.038 ** & -0.014 & $-0.045^{* *}$ & $-0.047^{* *}$ & 0.003 & -0.018 \\
\hline $\begin{array}{l}\text { high } \\
\text { stock 13-18 }\end{array}$ & $-0.081 * *$ & -0.038 ** & $-0.033 *$ & 0.007 & $-0.046 * *$ & $-0.051^{* *}$ & $-0.031 * *$ \\
\hline low & $-0.060 * *$ & -0.024 * & 0.010 & -0.001 & -0.020 & -0.007 & $-0.027^{*}$ \\
\hline medium & $-0.029 *$ & -0.022 & -0.016 & -0.035 & 0.010 & 0.036 & 0.004 \\
\hline high & -0.038 & -0.031 & -0.025 & 0.014 & -0.025 & $-0.048 *$ & -0.035 * \\
\hline $\begin{array}{l}\text { LR Test Heterogeneity } \\
(\mathrm{DF}=8)\end{array}$ & 7.520 & 6.906 & 18.408 ** & 7.376 & 13.206 & 16.500 ** & 14.216 * \\
\hline $\mathrm{N}$ & 587 & 783 & 1003 & 670 & 850 & 542 & 423 \\
\hline
\end{tabular}

Notes: Average partial effects (APE) based on Maximum likelihood estimates implementing the Wooldridge (2005) initial condition solution. Initial condition estimates not shown but can be provided upon request. APE are calculated using the numerical deriva 
Table 11 Employment Rate Differences by Region and Education in Spain and Italy

\begin{tabular}{lrrrrrr}
\hline \hline & \multicolumn{3}{c}{ 1994 } & & & 2001 \\
Italy & low & med/high & total & low & med/high & total \\
\cline { 2 - 7 } North West & 0.314 & 0.678 & 0.543 & 0.429 & 0.729 & 0.617 \\
Lombardia & 0.644 & 0.738 & 0.700 & 0.565 & 0.738 & 0.667 \\
North East & 0.519 & 0.676 & 0.608 & 0.426 & 0.775 & 0.624 \\
Emilia-Romagna & 0.643 & 0.829 & 0.776 & 0.857 & 0.833 & 0.840 \\
Center & 0.477 & 0.662 & 0.587 & 0.477 & 0.677 & 0.596 \\
Lazio & 0.179 & 0.550 & 0.333 & 0.214 & 0.600 & 0.375 \\
Abruzzo-Molise & 0.395 & 0.500 & 0.446 & 0.316 & 0.529 & 0.417 \\
Campania & 0.111 & 0.603 & 0.385 & 0.093 & 0.632 & 0.393 \\
South & 0.206 & 0.561 & 0.368 & 0.224 & 0.610 & 0.405 \\
Sicilia & 0.043 & 0.591 & 0.311 & 0.087 & 0.614 & 0.344 \\
Sardegna & 0.111 & 0.524 & 0.263 & 0.167 & 0.619 & 0.333 \\
\hline Spain & low & med/high & total & low & med/high & total \\
\hline Nort West & 0.224 & 0.353 & 0.272 & 0.351 & 0.471 & 0.396 \\
North East & 0.219 & 0.647 & 0.409 & 0.281 & 0.800 & 0.509 \\
Madrid & 0.357 & 0.535 & 0.447 & 0.326 & 0.571 & 0.447 \\
Center & 0.141 & 0.472 & 0.246 & 0.244 & 0.417 & 0.298 \\
East & 0.296 & 0.596 & 0.430 & 0.472 & 0.724 & 0.585 \\
South & 0.154 & 0.275 & 0.200 & 0.250 & 0.463 & 0.333 \\
Canarias & 0.154 & 0.600 & 0.226 & 0.154 & 1.000 & 0.290 \\
\hline \hline
\end{tabular}

Notes: employment rates by region and education level. 
Table 12 Regional Employment Regressions based on ECHP for Spain, Italy and Germany

\begin{tabular}{|c|c|c|c|c|c|c|c|c|c|}
\hline \multirow[b]{2}{*}{ Variable } & \multicolumn{3}{|c|}{ Spain } & \multicolumn{3}{|c|}{ Italy } & \multicolumn{3}{|c|}{ Germany } \\
\hline & 1 & 2 & 3 & 1 & 2 & 3 & 1 & 2 & 3 \\
\hline \multicolumn{10}{|c|}{ Year Dummies $(\operatorname{Ref}=1994)$} \\
\hline \multirow[t]{2}{*}{1995} & 0.015 & 0.013 & 0.017 & 0.001 & 0.002 & -0.001 & -0.001 & -0.001 & 0.004 \\
\hline & 1.33 & 1.27 & 1.7 & -0.03 & 0.31 & -0.11 & -0.1 & -0.07 & 0.27 \\
\hline \multirow[t]{2}{*}{1996} & 0.021 & 0.005 & 0.016 & 0.007 & -0.001 & 0.004 & 0.001 & 0.001 & 0.004 \\
\hline & 1.97 & 0.41 & 1.36 & 1.04 & -0.13 & 0.56 & 0.1 & 0.09 & 0.25 \\
\hline \multirow[t]{2}{*}{1997} & 0.042 & 0.008 & 0.018 & 0.013 & -0.003 & 0.010 & -0.020 & -0.017 & -0.016 \\
\hline & 3.88 & 0.45 & 1.02 & 1.96 & -0.23 & 0.93 & -1.41 & -0.96 & -0.91 \\
\hline \multirow[t]{2}{*}{1998} & 0.069 & 0.014 & 0.034 & 0.027 & 0.005 & 0.013 & -0.024 & -0.021 & -0.014 \\
\hline & 6.35 & 0.56 & 1.31 & 4.23 & 0.34 & 0.95 & -1.75 & -1.12 & -0.71 \\
\hline \multirow[t]{2}{*}{1999} & 0.096 & 0.026 & 0.048 & 0.038 & 0.010 & 0.023 & 0.003 & 0.007 & 0.008 \\
\hline & 8.81 & 0.83 & 1.52 & 5.87 & 0.53 & 1.38 & 0.2 & 0.32 & 0.32 \\
\hline \multirow[t]{2}{*}{2000} & 0.116 & 0.022 & 0.054 & 0.050 & 0.016 & 0.030 & 0.014 & 0.019 & 0.030 \\
\hline & 10.66 & 0.53 & 1.28 & 7.81 & 0.67 & 1.44 & 1.02 & 0.79 & 1.18 \\
\hline \multirow[t]{2}{*}{2001} & 0.148 & 0.054 & 0.085 & 0.070 & 0.038 & 0.052 & 0.025 & 0.031 & 0.047 \\
\hline & 13.56 & 1.33 & 2.05 & 10.91 & 1.64 & 2.62 & 1.84 & 1.22 & 1.74 \\
\hline \multirow[t]{2}{*}{ log wage } & & 0.304 & 0.182 & & 0.116 & 0.134 & & -0.025 & -0.003 \\
\hline & & 2.36 & 1.43 & & 1.46 & 1.9 & & -0.25 & -0.03 \\
\hline \multirow[t]{2}{*}{$\%$ public } & & & -0.292 & & & 0.084 & & & 0.512 \\
\hline & & & -1.38 & & & 0.8 & & & 3.35 \\
\hline wage gap & & & -0.126 & & & 0.120 & & & -0.047 \\
\hline public & & & -1.19 & & & 4.25 & & & -0.93 \\
\hline wage gap & & & 0.217 & & & -0.028 & & & -0.008 \\
\hline education & & & 3.21 & & & -0.87 & & & -0.42 \\
\hline \multirow[t]{2}{*}{$\%$ part-time } & & & 0.211 & & & 0.180 & & & -0.289 \\
\hline & & & 0.56 & & & 2.61 & & & -1.51 \\
\hline $\mathrm{N}$ & 56 & 56 & 56 & 88 & 88 & 88 & 120 & 120 & 120 \\
\hline r2 & 0.95 & 0.96 & 0.97 & 0.99 & 0.99 & 0.99 & 0.61 & 0.61 & 0.67 \\
\hline
\end{tabular}

Notes: Based on regional aggregates from the ECHP. See the appendix for detail on construction of the variables. 
Table 13 Social Norms Related to Employment by Gender, Region, and Education in Italy

\begin{tabular}{|c|c|c|c|c|c|c|}
\hline \multicolumn{7}{|c|}{ When jobs are scarce: men should have more right to a job than women } \\
\hline \multirow[t]{2}{*}{ All } & \multicolumn{3}{|c|}{ Low Educated } & \multicolumn{3}{|c|}{ Middle/High Educated } \\
\hline & Agree & Disagree & Neither & Agree & Disagree & Neither \\
\hline \multirow[t]{2}{*}{ North } & 34.86 & 44.00 & 21.14 & 13.61 & 68.97 & 17.42 \\
\hline & 122 & 154 & 74 & 75 & 380 & 96 \\
\hline \multirow[t]{2}{*}{ Centre } & 40.82 & 42.86 & 16.33 & 16.73 & 68.53 & 14.74 \\
\hline & 100 & 105 & 40 & 42 & 172 & 37 \\
\hline \multirow[t]{2}{*}{ South } & 51.75 & 33.85 & 14.40 & 18.65 & 70.10 & 11.25 \\
\hline & 133 & 87 & 37 & 58 & 218 & 35 \\
\hline \multirow[t]{2}{*}{ Females } & \multicolumn{3}{|c|}{ Low Educated } & \multicolumn{3}{|c|}{ Middle/High Educated } \\
\hline & Agree & Disagree & Neither & Agree & Disagree & Neither \\
\hline \multirow[t]{2}{*}{ North } & 39.68 & 43.92 & 16.40 & 13.67 & 75.18 & 11.15 \\
\hline & 75 & 83 & 31 & 38 & 209 & 31 \\
\hline \multirow[t]{2}{*}{ Centre } & 45.45 & 39.39 & 15.15 & 11.29 & 72.58 & 16.13 \\
\hline & 60 & 52 & 20 & 14 & 90 & 20 \\
\hline \multirow[t]{2}{*}{ South } & 50.00 & 38.73 & 11.27 & 12.34 & 79.22 & 8.44 \\
\hline & 71 & 55 & 16 & 19 & 122 & 13 \\
\hline \multirow[t]{2}{*}{ Males } & \multicolumn{3}{|c|}{ Low Educated } & \multicolumn{3}{|c|}{ Middle/High Educated } \\
\hline & Agree & Disagree & Neither & Agree & Disagree & Neither \\
\hline \multirow[t]{2}{*}{ North } & 29.19 & 44.10 & 26.71 & 13.55 & 62.64 & 23.81 \\
\hline & 47 & 71 & 43 & 37 & 171 & 65 \\
\hline \multirow[t]{2}{*}{ Centre } & 35.40 & 46.90 & 17.70 & 22.05 & 64.57 & 13.39 \\
\hline & 40 & 53 & 20 & 28 & 82 & 17 \\
\hline \multirow[t]{2}{*}{ South } & 53.91 & 27.83 & 18.26 & 24.84 & 61.15 & 14.01 \\
\hline & 62 & 32 & 21 & 39 & 96 & 22 \\
\hline
\end{tabular}

